\title{
Traits of sub-kilometre F-region irregularities as seen with the Swarm satellites
}

\author{
Sharon Aol ${ }^{1}$, Stephan Buchert ${ }^{2}$, and Edward Jurua ${ }^{1}$ \\ ${ }^{1}$ Department of Physics, Mbarara University of Science and Technology, Mbarara, Uganda \\ ${ }^{2}$ Swedish Institute of Space Physics, Uppsala, Sweden
}

Correspondence: Sharon Aol (sharonaol@ymail.com)

Received: 25 March 2019 - Discussion started: 15 April 2019

Revised: 17 January 2020 - Accepted: 20 January 2020 - Published: 19 February 2020

\begin{abstract}
During the night, in the F-region, equatorial ionospheric irregularities manifest as plasma depletions observed by satellites, and they may cause radio signals to fluctuate. In this study, the distribution characteristics of ionospheric F-region irregularities in the low latitudes were investigated using $16 \mathrm{~Hz}$ electron density observations made by a faceplate which is a component of the electric field instrument (EFI) onboard Swarm satellites of the European Space Agency (ESA). The study covers the period from October 2014 to October 2018 when the $16 \mathrm{~Hz}$ electron density data were available. For comparison, both the absolute $\left(d N_{\mathrm{e}}\right)$ and relative $\left(d N_{\mathrm{e}} / N_{\mathrm{e}}\right)$ density perturbations were used to quantify the level of ionospheric irregularities. The two methods generally reproduced the local-time (LT), seasonal and longitudinal distribution of equatorial ionospheric irregularities as shown in earlier studies, demonstrating the ability of Swarm $16 \mathrm{~Hz}$ electron density data. A difference between the two methods was observed based on the latitudinal distribution of ionospheric irregularities where $\left(d N_{\mathrm{e}}\right)$ showed a symmetrical distribution about the magnetic equator, while $d N_{\mathrm{e}} / N_{\mathrm{e}}$ showed a magnetic-equator-centred Gaussian distribution. High values of $d N_{\mathrm{e}}$ and $d N_{\mathrm{e}} / N_{\mathrm{e}}$ were observed in spatial bins with steep gradients of electron density from a longitudinal and seasonal perspective. The response of ionospheric irregularities to geomagnetic and solar activities was also investigated using $\mathrm{Kp}$ index and solar radio flux index (F10.7), respectively. The reliance of $d N_{\mathrm{e}} / N_{\mathrm{e}}$ on solar and magnetic activity showed little distinction in the correlation between equatorial and off-equatorial latitudes, whereas $d N_{\mathrm{e}}$ showed significant differences. With regard to seasonal and longitudinal distribution, high $d N_{\mathrm{e}}$ and $d N_{\mathrm{e}} / N_{\mathrm{e}}$ values were often found during quiet magnetic periods compared to
\end{abstract}

magnetically disturbed periods. The $d N_{\mathrm{e}}$ increased approximately linearly from low to moderate solar activity. Using the high-resolution faceplate data, we were able to identify ionospheric irregularities on the scale of only a few hundred of metres.

\section{Introduction}

Noticeable features in the low-latitude ionosphere are plasma density irregularities which occur after sunset in the $\mathrm{F}$ region (Kil and Heelis, 1998). They may be identified as density decrease along satellite passes referred to as equatorial plasma bubbles (EPBs) or range and frequency spread signatures on ionograms commonly called equatorial spread $\mathrm{F}$ (ESF) (Woodman and La Hoz, 1976; Burke et al., 2004). The generalized Rayleigh-Taylor instability (RTI) is the suggested mechanism which can explain how ionospheric irregularities occur in the low latitudes (Woodman and La Hoz, 1976; Gentile et al., 2006; Portillo et al., 2008; Nishioka et al., 2008; Kelley, 2009; Schunk and Nagy, 2009). They may cause disruptions in trans-ionospheric radio signals of frequencies ranging from a few hundred kilohertz to several gigahertz, which in turn degrade the performance of communication and navigation systems (Kil and Heelis, 1998; Kintner et al., 2007).

There are many studies on the distribution characteristics of equatorial ionospheric irregularities (e.g. Kil and Heelis, 1998; Huang et al., 2002; Burke et al., 2004; Makela et al., 2004; Park et al., 2005; Su et al., 2006; Stolle et al., 2006; Kil et al., 2009; Dao et al., 2011; Xiong et al., 2012; Carter et al., 2013; Huang et al., 2014; Costa et al., 2014). Long-term 
observations of equatorial ionospheric irregularities have shown that their occurrence depends on various geophysical parameters including longitude, latitude, altitude, local time (LT), season, solar activity and geomagnetic conditions (Kil et al., 2009). The dependence of ionospheric irregularities on the geophysical parameters, however, remains a problem in modelling their variation for predictive purposes (Yizengaw and Groves, 2018). Therefore, further global-scale studies on the distribution characteristics of ionospheric irregularities and their dependence on various factors are still necessary. An interesting feature of these plasma irregularities is their scale sizes. They typically cover a variety of scale sizes, from a few centimetres to thousands of kilometres (Zargham and Seyler, 1989; Hysell and Seyler, 1998). The metre scales correspond to radio waves at a high frequency (HF) and very high frequency (VHF), where irregularities are associated with Bragg scattering of radio waves and the spread-F phenomenon (Woodman, 2009). The in situ measurements by satellites are normally suitable for analysing the global aspects of the statistics of ionospheric irregularities. Depending on the sampling rate, spatial scales from about $100 \mathrm{~m}$ and larger can be seen. However, the orbital characteristics of satellite missions can limit the statistical coverage regarding altitude, latitude, local time, solar cycle phase, seasons, longitude and aspect angle with respect to the geomagnetic field. Stolle et al. (2006) used magnetic observations made by the polar-orbiting CHAllenging Minisatellite Payload (CHAMP) satellite for the years 2001-2004 to study the irregularities. Multi-peak electron density fluctuations were not observed in the results presented by Stolle et al. (2006) due to the low sampling rate of the planar Langmuir probe (LP; PLP) measurements. However, the CHAMP satellite's magnetic field data recorded at a frequency of $50 \mathrm{~Hz}$ showed irregularity structures as small as $50 \mathrm{~m}$ in scale size (Stolle et al., 2006). Multiple studies have also used high-resolution data sets when available to check the distribution characteristics of ionospheric irregularities and have been able to resolve plasma density structures to smaller scales along satellite tracks (e.g. Lühr et al., 2014; Huang et al., 2014, etc.).

The launch of the first Earth observation constellation mission of the European Space Agency (ESA), i.e. Swarm, in 22 November 2013, generated new interests in the study of ionospheric irregularities. Each satellite is equipped with an electric field instrument (EFI) in addition to other payloads. The EFI consists of LPs and thermal ion imagers (TIIs) (Knudsen et al., 2017). A number of studies have demonstrated the use of Swarm satellites for observations of ionospheric irregularities (e.g. Buchert et al., 2015; Zakharenkova et al., 2016; Xiong et al., 2016b, c; Wan et al., 2018; Yizengaw and Groves, 2018; Jin et al., 2019; Kil et al., 2019, etc.). Most of these studies have used electron density measurements at a frequency of $2 \mathrm{~Hz}$ or $1 \mathrm{~Hz}$ made by the Langmuir probes onboard Swarm. Xiong et al. (2016c) used Swarm $2 \mathrm{~Hz}$ electron density measurements to check the scale sizes of irregularity structures. They suggested that the structures have scale sizes in the zonal direction less than $44 \mathrm{~km}$. The Swarm satellites have the capability of measuring electron density at an even higher frequency of $16 \mathrm{~Hz}$ by determining the current through a faceplate. This plate is electrically isolated from the satellite, negatively biased and located on the ram side such that positive ions make impact on the relatively large surface of about $26 \times 26 \mathrm{~cm}^{2}$ with super-thermal velocity due to orbital motion (Buchert, 2016). As a result, the electron density can be readily estimated from the current at a relatively high rate of $16 \mathrm{~Hz}$. The faceplate acts like a planar LP, however, without the possibility of sweeps and temperature measurements. Operation of the TII requires a bias value which turned out to be unsuitable for density estimation. Therefore, the $16 \mathrm{~Hz}$ density estimates are only provided when the TII is inactive (Buchert, 2016). Swarm can record ionospheric irregularities of scale lengths up to $500 \mathrm{~m}$ along their tracks using the $16 \mathrm{~Hz}$ electron density measurements. High-resolution data enable smaller-scale structures to be identified in electron density (Nishioka et al., 2011). The $16 \mathrm{~Hz}$ electron density data from Swarm satellite have not yet been used to study traits of ionospheric irregularities. In the present study, we looked at the distribution characteristics of equatorial ionospheric irregularities using $16 \mathrm{~Hz}$ faceplate measurements of electron density. The study covers the period from October 2014 to October 2018 corresponding to the descending phase of solar cycle 24 , when the $16 \mathrm{~Hz}$ electron density data were available. We show that the electron density measurements of the Swarm faceplate can be applied to examine the characteristics of ionospheric equatorial irregularities at sub-kilometre scale lengths.

The rest of the paper is organized in the following order: the data and methods are presented in Sect. 2. The results are presented and discussed in Sect. 3. The summary and conclusions are presented in Sect. 4.

\section{Data and methods}

The Swarm mission is made up of three of the same satellites (Swarm A, B and C) with an orbital speed of around $7.5 \mathrm{~km} \mathrm{~s}^{-1}$ in polar orbits. The Swarm satellites simultaneously measure the electron density $\left(N_{\mathrm{e}}\right)$, electron temperature $\left(T_{\mathrm{e}}\right)$ and spacecraft potential at a frequency of $2 \mathrm{~Hz}$ along the satellites' track with the LPs. The Swarm satellites also measure $N_{\mathrm{e}}$ at a frequency of $16 \mathrm{~Hz}$ with a faceplate. The plasma density is derived from the faceplate current assuming that it is carried by ions hitting the faceplate due to the orbital motion of the spacecraft (Buchert, 2016). Knudsen et al. (2017) provide more details on how electron density is derived from the LPs and TII. Using Swarm mission data collected from October 2014 to October 2018, orbit analysis was carried out to check on the status of the Swarm orbits. From the orbit analysis, by the end of October 2018, the longitudinal separation between Swarm A and C was about $1.4^{\circ}$ corresponding to about $160 \mathrm{~km}$ distance at the Equator, covering 
nearly the same local-time sector with a time lag of about 1-10 s. The time lag between Swarm B and the lower pairs reached up to $8 \mathrm{~h}$. Swarm A and C were orbiting at an altitude of about $448 \mathrm{~km}$ (orbital inclination angle of $87.35^{\circ}$ ) above sea level over the low-latitude region, and Swarm B was orbiting at an altitude of about $512 \mathrm{~km}$ (orbital inclination angle of $87.75^{\circ}$ ). In a day, the swarm satellites complete about 16 orbits with an average orbital period of about $91.5 \mathrm{~min}$. Swarm satellites regress in longitude around $22.5^{\circ}$ between orbital ascending nodes. Data sets measured by Swarm can be downloaded from http://earth.esa.int/swarm, last access: 23 February 2020. The investigations done in this study are based on the $16 \mathrm{~Hz} N_{\mathrm{e}}$ faceplate data collected for the period of October 2014 to October 2018.

The identification criteria adopted for quantifying ionospheric irregularities have been a matter of concern. Some earlier studies (e.g. Kil and Heelis, 1998; McClure et al., 1998; Burke et al., 2003; Su et al., 2006; Kil et al., 2009; Dao et al., 2011, etc.) used relative plasma density disturbance to identify ionospheric irregularities, while others (e.g. Lühr et al., 2014; Buchert et al., 2015; Xiong et al., 2016b, etc.) took absolute density disturbance. However, Huang et al. (2014) used the $512 \mathrm{~Hz}$ Communication/Navigation Outage Forecasting System (C/NOFS) satellite's measurements of ion density and found that when the relative and absolute density disturbances are used independently, the likelihood of irregularities occurring and their variation with local time differ. The C/NOFS satellite was in a low-tilt orbit, so the bubbles were sampled zonally. Important differences basing on latitudinal distribution of ionospheric irregularities using different criteria could not be addressed by Huang et al. (2014). The polar-orbiting Swarm satellites sample bubbles in a meridional direction, and they give an opportunity to check the difference in the latitudinal distribution of irregularities using different identification criteria. The Swarm satellites cover mainly small aspect angles with respect to the magnetic field near the Equator, while C/NOFS included mainly nearly field-perpendicular density variations. Chartier et al. (2018) used $N_{\mathrm{e}}$ and total electron content (TEC) measurements made by the LPs and GPS, respectively, onboard Swarm to test the relative and absolute perturbations in the detection of polar cap patches. In terms of seasonal distribution, they observed discrepancies between the two methods with relative disturbances showing more patches in winter than in summer. However, the study presented by Chartier et al. (2018) was limited to high latitudes.

For comparison purposes, two methods were also adopted for the polar-orbiting Swarm satellites to quantify the level of electron density irregularities in the low-latitude region. In the first method, the $16 \mathrm{~Hz} N_{\mathrm{e}}$ measurements were passed through a $2 \mathrm{~s}$ running mean filter (with 32 data points) corresponding to a wavelength of about $15 \mathrm{~km}$. From the original observations, the filtered data were subtracted to obtain the residual $d N_{\mathrm{e}}=N_{\mathrm{e}}-\bar{N}_{\mathrm{e}}$, where $\bar{N}_{\mathrm{e}}$ is the mean of $N_{\mathrm{e}}$ at a $2 \mathrm{~s}$ interval. The standard deviation of the residuals which represents the density perturbation, $d N_{\mathrm{e}}$, was then calculated for all of the 32 data points. Basu et al. (1976) found that, on a global scale, absolute density perturbation equal to $1 \times$ $10^{-10} \mathrm{~m}^{-3}$ represents the percentage occurrence of $140 \mathrm{MHz}$ scintillations. Xiong et al. (2010) used absolute density disturbance thresholds of $5 \times 10^{10} \mathrm{~m}^{-3}$ and $3 \times 10^{10} \mathrm{~m}^{-3}$, respectively, to identify density irregularity structures on CHAMP and GRACE observations. Wan et al. (2018) adopted an absolute density perturbation of $>5 \times 10^{10} \mathrm{~m}^{-3}$ to identify ionospheric irregularities from Swarm. Based on the method used in the current study, only batches with a $d N_{\mathrm{e}}$ value greater than $0.25 \times 10^{10} \mathrm{~m}^{-3}$ were considered to be significantly irregular and selected for extra processing and analysis. In the second method, $d N_{\mathrm{e}}$ was divided by $\bar{N}_{\mathrm{e}}$ to obtain the relative perturbation, $d N_{\mathrm{e}} / N_{\mathrm{e}}$. There is no specific threshold definition to be used when $d N_{\mathrm{e}} / N_{\mathrm{e}}$ identifies irregularities (Huang et al., 2014; Wan et al., 2018). Kil and Heelis (1998) determined the likelihood of occurrence of relative disturbance of $>1 \%(0.01)$ and $5 \%(0.05)$ from Atmosphere Explorer E (AE-E) satellite data. The AE-E satellite data were also used by McClure et al. (1998), but relative disturbances $>0.5 \%(0.005)$ were used to identify irregularities. To identify the occurrence of ROCSAT- 1 irregularities, Su et al. (2006) and Kil et al. (2009) used a threshold of 0.3\% (0.003) for the relative disturbance. Huang et al. (2014) used high-resolution ion density measurements from the C/NOFS satellite and took a relative perturbation of $>1 \%(0.01)$. Wan et al. (2018) considered relative perturbation values larger than $20 \%$. In the current study, only batches with a $\left(d N_{\mathrm{e}} / N_{\mathrm{e}}\right.$ value of $>0.01$ were considered to be significantly irregular and used for further analysis based on the methods adopted. Here, we mostly dealt with small-scale ionospheric irregularities which are relevant for L-band scintillations. It is essential to note that these small-scale irregularities are not autonomous from those of large-scale ionospheric irregularities, and they were not differentiated. The only satellite sampling the bottom side, at altitudes below $300 \mathrm{~km}$, has so far been the Atmosphere Explorer E (Kil and Heelis, 1998). With the AE-E satellite, irregularities with relatively small amplitudes were seen without clearly developed EPBs. At altitudes above $350 \mathrm{~km}$ addressed by nearly all other studies, smaller-scale irregularities are usually embedded in EPBs. Automatic detection algorithms used in previous works do not discriminate between depletions (EPBs) and irregular multi-peak variations, with the exception of Wan et al. (2018), whose algorithm determined a depletion amplitude. The results are presented and discussed in the following section.

\section{Results and discussions}

The high-resolution Swarm faceplate $N_{\mathrm{e}}$ data were used to characterize ionospheric irregularities using procedures described in Sect. 2. 

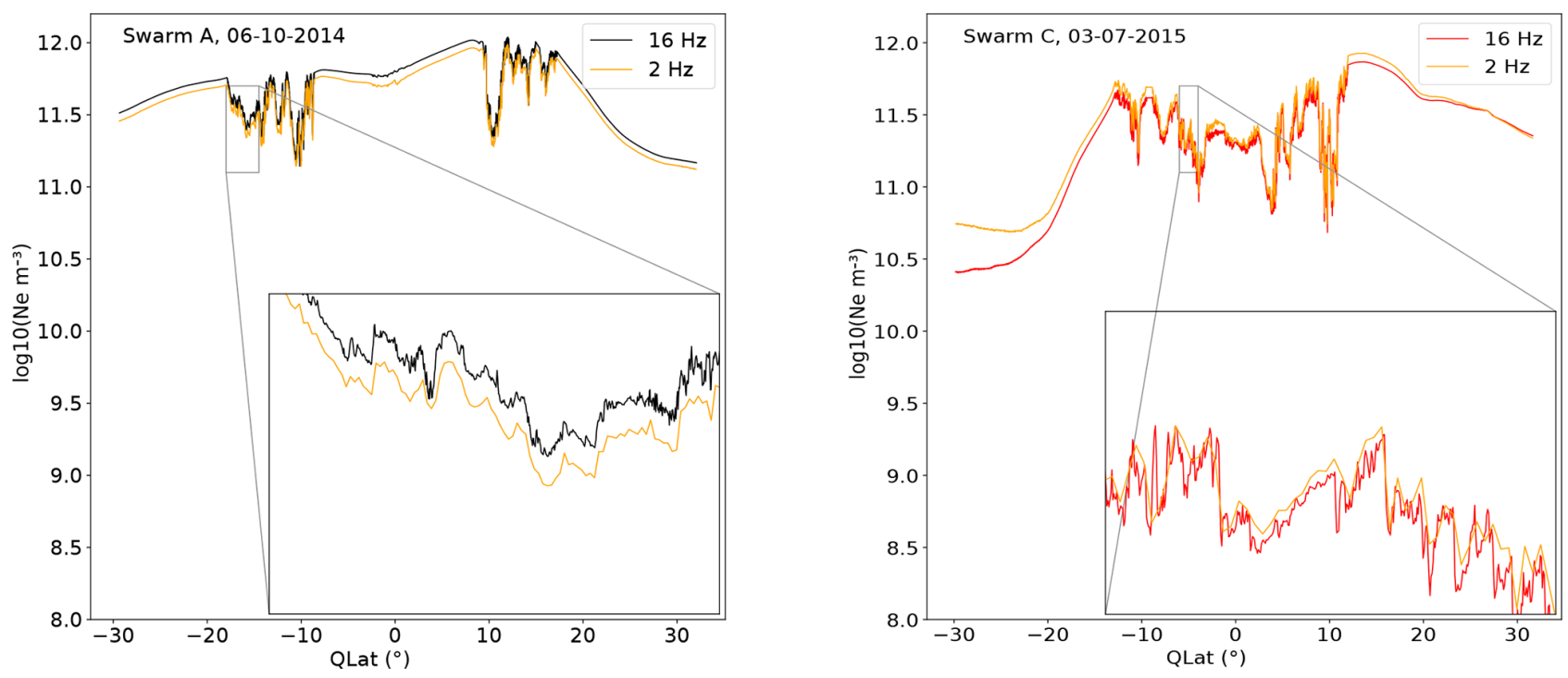

Figure 1. Comparison of $2 \mathrm{~Hz} \mathrm{LP}$ data and $16 \mathrm{~Hz}$ faceplate data for Swarm A and C on 6 October 2014 and 3 July 2015 , respectively.

Table 1. Summary of yearly total Swarm satellite passes over the low-latitude region for which $16 \mathrm{~Hz}$ data were recorded.

\begin{tabular}{lrrrrr|r}
\hline Satellite & \multicolumn{5}{c|}{$\begin{array}{c}\text { Total Swarm satellite } \\
\text { passes per year }\end{array}$} & $\begin{array}{c}\text { Total passes } \\
\text { per satellite }\end{array}$ \\
\hline Year & 2014 & 2015 & 2016 & 2017 & 2018 & \\
Swarm A & 711 & 7158 & 6670 & 6520 & 4242 & 25301 \\
Swarm C & 891 & 1390 & 8208 & 7101 & 5748 & 23068 \\
Swarm B & 1127 & 7836 & 7522 & 7017 & 2895 & 26397 \\
\hline
\end{tabular}

Figure 1 shows examples of $N_{\mathrm{e}}$ results for arbitrary passes of Swarm A and C on 6 October 2014 and 3 July 2015, respectively, from the LP and faceplate to highlight the capability of the $16 \mathrm{~Hz} N_{\mathrm{e}}$ data for observations of irregularity density structures. In Fig. 1, the orange curve is the time series of the $2 \mathrm{~Hz} \mathrm{LP}$ data, while the black and red curves are the time series of the $16 \mathrm{~Hz}$ faceplate data for Swarm A and $\mathrm{C}$, respectively. Both the 16 and $2 \mathrm{~Hz} N_{\mathrm{e}}$ data show large density depletion along the satellite tracks concentrated at about $\pm 15^{\circ}$ of quasi-dipole latitude (QLat). The $16 \mathrm{~Hz} N_{\mathrm{e}}$ data were able to capture fluctuations in $N_{\mathrm{e}}$ just as the $2 \mathrm{~Hz}$ data. However, smaller-scale electron density depletions in $N_{\mathrm{e}}$ cannot be verified with the low-resolution $2 \mathrm{~Hz}$ data as shown in the zoomed-in sections in Fig. 1. One of the drawbacks associated with the $16 \mathrm{~Hz} N_{\mathrm{e}}$ data, as mentioned earlier, is that they are only recorded when the TII is inactive. Therefore, to check data availability, Table 1 summarizes the number of satellite passes per year for which $16 \mathrm{~Hz} N_{\mathrm{e}}$ data were recorded. We used all the passes available as summarized in Table 1 and later realized that data accumulation for the period of study was enough for a climatology study.

Examples of Swarm's encounters with ionospheric irregularities are presented in Fig. 2. Figure 2a shows multiple
$N_{\mathrm{e}}$ depletions occurring between about $\pm 10^{\circ}- \pm 20^{\circ}$ QLat. From Fig. $2 \mathrm{~b}$ and c, large values of both $d N_{\mathrm{e}}$ and $d N_{\mathrm{e}} / N_{\mathrm{e}}$ often occur in locations of large depletions in $N_{\mathrm{e}}$ at the equatorial ionization anomaly (EIA) crests close to the quasi-dipole equator but also at the bottom of large scale bubbles. Based on the thresholds defined in Sect. $2\left(d N_{\mathrm{e}}>0.25 \times 10^{10} \mathrm{~m}^{-3}\right.$ and $\left.d N_{\mathrm{e}} / N_{\mathrm{e}}>0.01\right)$ to identify plasma density structures, these depletions are ionospheric irregularities. The RTI is the most known mechanism that causes irregularities in low latitudes (Kelley, 2009; Kintner et al., 2007). The lowerionospheric layer declines rapidly during the night compared to the top layer. This creates a sharp vertical gradient of plasma density directed upwards, contrary to the gravitational force's direction of action. For such unstable arrangement, irregularities in the $\mathrm{F}$ region at the bottom intensify and drift up, creating more complex plasma structures that extend to higher altitudes along magnetic field lines (Woodman and La Hoz, 1976; Abdu, 2005; Kelley, 2009). In general, ionospheric irregularities are more intense at the equatorial ionization anomaly belts $\left( \pm 15^{\circ}\right.$ QLat $)$ than at the geomagnetic equator as observed in Fig. 2. However, from Fig. 2, the event presented for Swarm A and C on 7 July 2015 shows high values of $d N_{\mathrm{e}} / N_{\mathrm{e}}$ even at the magnetic equator. Huang et al. (2014) also observed that the relative and absolute perturbations were both able to capture fluctuations in ion density measurements made along C/NOFS tracks during 20082012 in the zonal direction. However, it was not possible to see a more detailed latitude distribution using C/NOFS satellite because it covered a small latitude range of about $\pm 13^{\circ}$ due to its low inclination angle of about $13^{\circ}$. The local-time distribution characteristics of ionospheric irregularities were also determined, and the results are presented and discussed in the following subsection. 

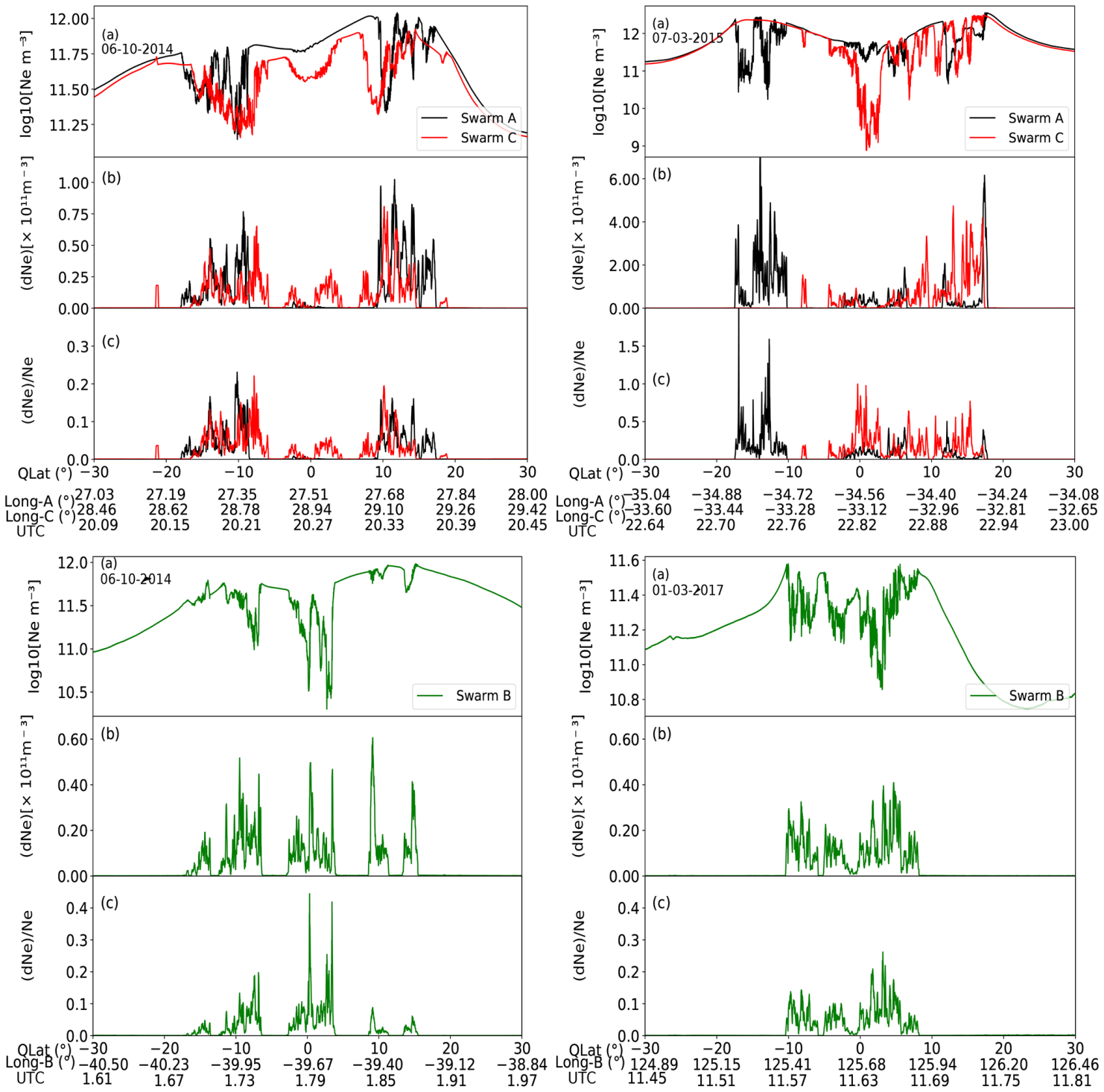

Figure 2. Irregularity structures observed by Swarm A, C and B. Panels (a) to (c) represent electron density $\left(N_{\mathrm{e}}\right)$ variation at $16 \mathrm{~Hz}$ in logarithmic scale, absolute $\left(d N_{\mathrm{e}}\right)$ and relative $\left(d N_{\mathrm{e}} / N_{\mathrm{e}}\right)$ electron density perturbations, respectively, as functions of QLat, geographic longitude (GLong) and universal time (UTC).

\section{1 local-time distribution of ionospheric irregularities}

It is known from many studies (e.g. Kil and Heelis, 1998; Burke et al., 2004; Su et al., 2006; Stolle et al., 2006; Dao et al., 2011; Huang et al., 2014; Xiong et al., 2016b; Wan et al., 2018, etc.) that ionospheric irregularities in the low latitudes occur after sunset. Here, we also check the localtime dependence of the ionospheric irregularities identified on the $N_{\mathrm{e}}$ data from the Swarm faceplate to compare with previous results.

Figure 3 presents the percentage occurrence of equatorial ionospheric irregularities as a function of local time based on $d N_{\mathrm{e}}$ in Fig. $3 \mathrm{a}$ and $d N_{\mathrm{e}} / N_{\mathrm{e}}$ in Fig. 3b. Using $16 \mathrm{~Hz} N_{\mathrm{e}}$ data accumulated during the period of study, the seasonal de- pendence of local-time distribution of ionospheric irregularities was also examined by grouping all the data into different seasons corresponding to the March equinox (FebruaryMarch-April), June solstice (May-June-July), September equinox (August-September-October) and December solstice (November-December-January). The number of irregularity structures was determined per a $1 \mathrm{~h}$ local-time bin by counting the number of irregularity structures in a bin divided by the total number of observations.

As mentioned earlier, ionospheric irregularities in the low latitudes are nighttime phenomena, and therefore, the analysis was restricted to the time period from 18:00 to 06:00 LT. From Fig. 3, it is seen that irregularities occur from 18:00 
(a) $\left(d N_{e}\right)$
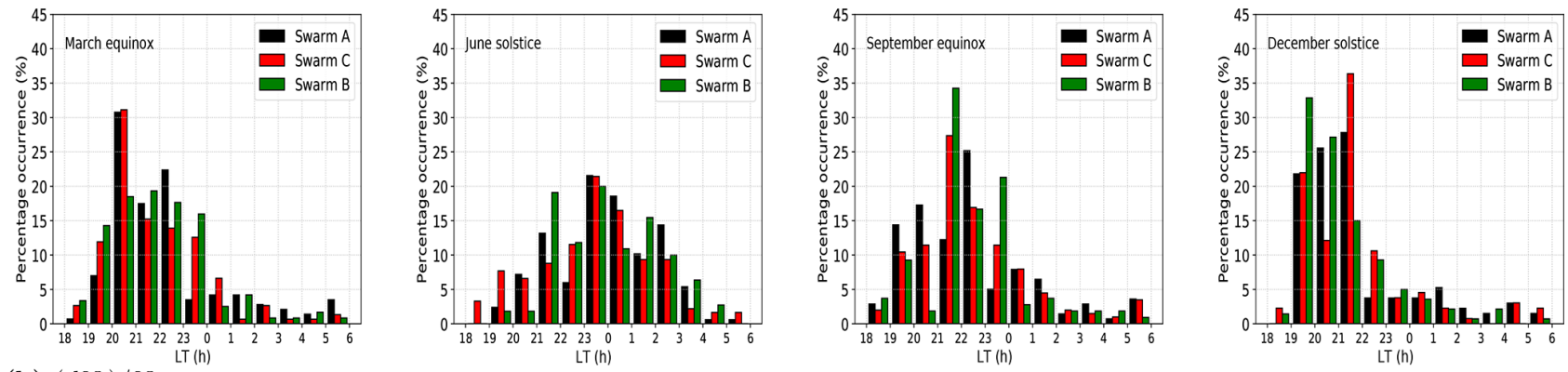

(b) $\left(d N_{e}\right) / N_{e}$
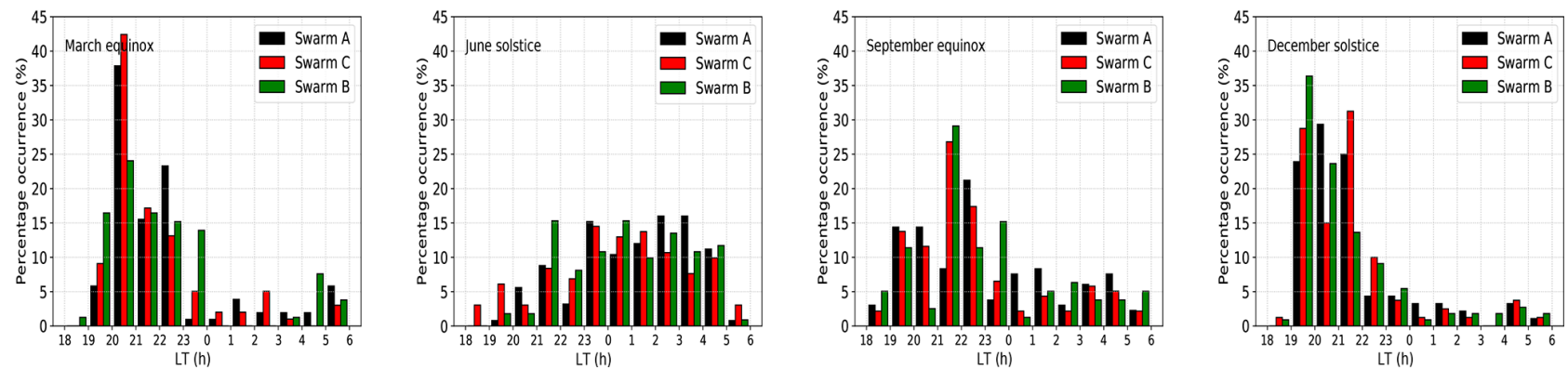

Figure 3. Histograms showing the percentage occurrence of (a) $d N_{\mathrm{e}}>0.25 \times 10^{10} \mathrm{~m}^{-3}$ and (b) $d N_{\mathrm{e}} / N_{\mathrm{e}}>0.01$ as a function of local time (LT) for the period from October 2014 to October 2018 for Swarm A, B and C. Each panel presents a season.

to 06:00 LT as expected, irrespective of the method used. In Fig. 3, the highest percentage occurrence is observed in the equinoxes and December solstice, where the percentage increases faster between 18:00 and 20:00 LT, attaining a maximum at about 21:00 LT, and then decreases gradually till the morning hours. The increase in percentage occurrence from 18:00 to 21:00 LT can be attributed to increased eastward electric fields produced by the eastward thermospheric wind's electrodynamic interaction at the day-night terminator around the dip equator with the geomagnetic field (Rishbeth, 1971; Su et al., 2009). The increase in the electric field to the east causes the night-side ionosphere to rise to higher altitudes where the RTI is favoured, and this increases the occurrence of ionospheric irregularities (Fejer et al., 1999; Abdu, 2005; Su et al., 2009). The percentage occurrence of ionospheric irregularities is low in the June solstice, and the percentage increase is slower with a wide plateau extending past midnight. According to Su et al. (2009), a late reversal of zonal drift associated with a small upward vertical post-sunset drift occurring at positive magnetic decline lengths in the June solstice significantly inhibits irregularities. For the case of $d N_{\mathrm{e}}$, the percentage occurrence reduces towards morning hours, while $d N_{\mathrm{e}} / N_{\mathrm{e}}$ maintains a high percentage occurrence past midnight in the June solstice. The percentage occurrence trend of $d N_{\mathrm{e}}$-based irregularities is like that of Kil and Heelis (1998), Palmroth et al. (2000), Burke et al. (2004), Su et al. (2006), Stolle et al. (2006), Su et al. (2009), Xiong et al. (2016b), Wan et al. (2018), etc. The $d N_{\mathrm{e}} / N_{\mathrm{e}}$ shows a nearly similar trend in percentage occurrence as for $d N_{\mathrm{e}}$ but with a high occurrence after midnight in the June solstice. An increase in post-midnight irregularities quantified by relative perturbations has also been observed by Huang et al. $(2011,2012,2014)$ and Dao et al. (2011) who used ion density measurements made by C/NOFS. The mechanisms that generate these post-midnight irregularities are still unknown and widely debated. Two mechanisms to explain the occurrence of post-midnight irregularities have been suggested. One mechanism is the seeding of the RTI by atmospheric gravitational waves from below into the ionosphere, while the other mechanism is the elevation of the $\mathrm{F}$ layer by the thermosphere's meridional neutral winds, which may be connected with the thermosphere's highest midnight temperature (Otsuka, 2018, and references therein).

The Global Positioning System SCINtillation Network and Decision Aid (GPS-SCINDA) has often been used as one of the tools for measuring variations in radio signals' amplitude and phase. In the absence of GPS-SCINDA, many studies (e.g. Basu et al., 1999; Yang and Liu, 2015; Yizengaw and Groves, 2018) have shown that the rate of change of TEC index (ROTI) derived from global navigation satellite system (GNSS) total electron content can be used as a proxy for quantifying scintillations. The ROTI is defined as the standard deviation of rate of change of TEC (ROT) (Pi et al., 1997). Numerous studies have widely discussed these 


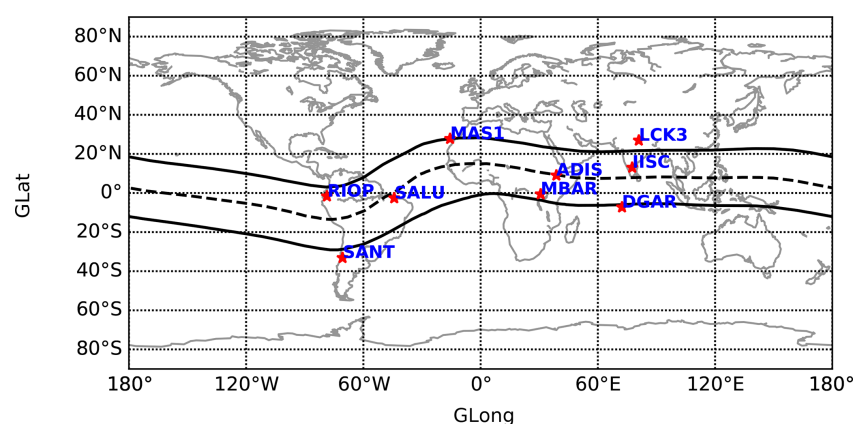

Figure 4. Map showing the location of IGS stations (red stars) considered in this study. The black dotted line represents the magnetic equator, while at about $\pm 15^{\circ}$ of magnetic latitude the black solid lines represent the EIA belts.

indices (e.g. Pi et al., 1997; Basu et al., 1999; Zou and Wang, 2009; Zakharenkova et al., 2016; Kumar, 2017; Yizengaw and Groves, 2018). We adopted ROTI to compare the groundbased local-time variations of irregularities or scintillations over different International GNSS Service (IGS) stations installed along the low-latitude region with the variations presented in Fig. 3. Xiong et al. (2016a) and Wan et al. (2018) developed an algorithm to determine depletion amplitudes and they showed that large depletion amplitudes of EPBs are relevant for causing radio signal disruptions at the Lband frequency. On the other hand, some previous studies have also stated the relevance of the small-scale $N_{\mathrm{e}}$ structures for causing L-band scintillations (e.g. Spogli et al., 2016; Lühr et al., 2014; Bhattacharyya et al., 2003; Rao et al., 1997). Sharma et al. (2018) suggested that small-scale structures may be abundantly available within the largely depleted EPBs, becoming the cause of L-band scintillation. Therefore, the results presented by Xiong et al. (2016a) and Wan et al. (2018) could be explained because deep EPBs involve steep density gradients and large background density which would create the small-scale irregularities. From the method used in our study, we mainly focused on irregularities of wavelength of about $15 \mathrm{~km}$ along the satellite track, and this is within the range of applicable Fresnel scales which is theoretically relevant as a cause of L-band scintillations. The IGS stations considered in this study are shown in Fig. 4 as red stars. The details of the IGS stations used are summarized in Table 2.

To find ROTI, only signals from GPS satellites with an elevation angle higher than $25^{\circ}$ over each independent station were considered to reduce the multipath effects. The ROTI values of $>0.5$ TECU min mi $^{-1}\left(1 \mathrm{TECU}=10^{16} \mathrm{el} \mathrm{m}^{-2}\right)$ were classified as irregularities or scintillations (Ma and Maruyama, 2006). Figure 5 presents the percentage occur-

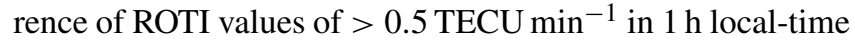
bins for the different IGS stations and seasons.

It is important to note that RIOP did not have TEC data in the June solstice and September equinox as seen in Fig. $5 \mathrm{~b}$ and c. In general, the trend followed by local-time distribution of ROTI seems to closely agree with that of $d N_{\mathrm{e}}$ and $d N_{\mathrm{e}} / N_{\mathrm{e}}$ in the equinoxes and December solstice. As expected the percentage occurrence of ionospheric irregularities is higher mainly for the IGS stations in the African longitude even in the June solstice (Yizengaw et al., 2014). The percentage occurrence in the June solstice is generally small, comparable to that observed in Fig. 3, with a broad plateau extending after midnight. However, the enhanced post-midnight irregularities seen in Fig. $3 \mathrm{~b}$ for $d N_{\mathrm{e}} / N_{\mathrm{e}}$ for the June solstice are not observed in the LT trend of ROTI. Therefore, the LT dependence of percentage occurrence of ionospheric irregularities quantified using $d N_{\mathrm{e}}$ closely follows the same trend as that of ROTI for all seasons. The seasonal and longitudinal distribution of ionospheric irregularities is presented in the following subsection.

\subsection{Seasonal and longitudinal distribution of ionospheric irregularities}

The Swarm mission's $16 \mathrm{~Hz} N_{\mathrm{e}}$ data collected over the 5-year period (2014-2018) have a credible global spatial and temporal coverage that is sufficiently good for examining the seasonal and longitudinal distribution of ionospheric irregularities in the low latitudes. To check the seasonal and longitudinal variation of ionospheric irregularities, we concentrate on satellite passes within the local-time range 18:00-06:00 LT. The $N_{\mathrm{e}}$ data for the period of study were divided into four seasons as described in Sect. 3.1. Swarm Equator crossings spanning the range of -40 to $+40^{\circ}$ were considered since the study narrows down to the low-latitude region. The $d N_{\mathrm{e}}$ and $d N_{\mathrm{e}} / N_{\mathrm{e}}$ were calculated in bins of $3^{\circ} \times 4^{\circ}$ resolution in geographic latitude and longitude. The occurrence rate of ionospheric irregularities does not always correspond to the highest amplitude of irregularity structures from the results presented by Wan et al. (2018). Therefore, here we concentrate on the magnitude of ionospheric irregularities other than the rate of occurrence. Zakharenkova et al. (2016) compared Swarm A and B $1 \mathrm{~s} N_{\mathrm{e}}$ data and revealed satellite-to-satellite differences related to altitude, longitude and local time. Here, we also show the results for all of the three satellites separately.

Figure 6 shows the seasonal and longitudinal distribution of $d N_{\mathrm{e}}$ during the period of study in geographic coordinates, while Fig. 7 presents that of $d N_{\mathrm{e}} / N_{\mathrm{e}}$ for Swarm A, C and B, independently, in the first, second and third columns, respectively. 
Table 2. Coordinates of IGS stations used in this study.

\begin{tabular}{lrrr}
\hline & \multicolumn{3}{c}{ Coordinates } \\
\cline { 2 - 4 } Station (code) & Geographic latitude $\left(^{\circ}\right)$ & Geographic longitude $\left(^{\circ}\right)$ & Magnetic latitude $\left(^{\circ}\right)$ \\
\hline Mbarara (MBAR) & -0.60 & 30.74 & -10.2 \\
Addis Ababa (ADIS) & 9.04 & 38.77 & 0.18 \\
Maspalomas (MAS1) & 27.76 & -15.63 & 15.63 \\
Riobamba (RIOP) & -1.65 & -78.65 & 10.56 \\
Santiago (SANT) & -33.15 & -70.67 & -19.52 \\
Sâo Luís (SALU) & -2.59 & -44.21 & -0.25 \\
Diego Garcia (DGAR) & -7.27 & 72.37 & -16.89 \\
Bengaluru (IISC) & 13.02 & 77.57 & 5.34 \\
Lucknow (LCK3) & 26.91 & 80.96 & 20.59 \\
\hline
\end{tabular}
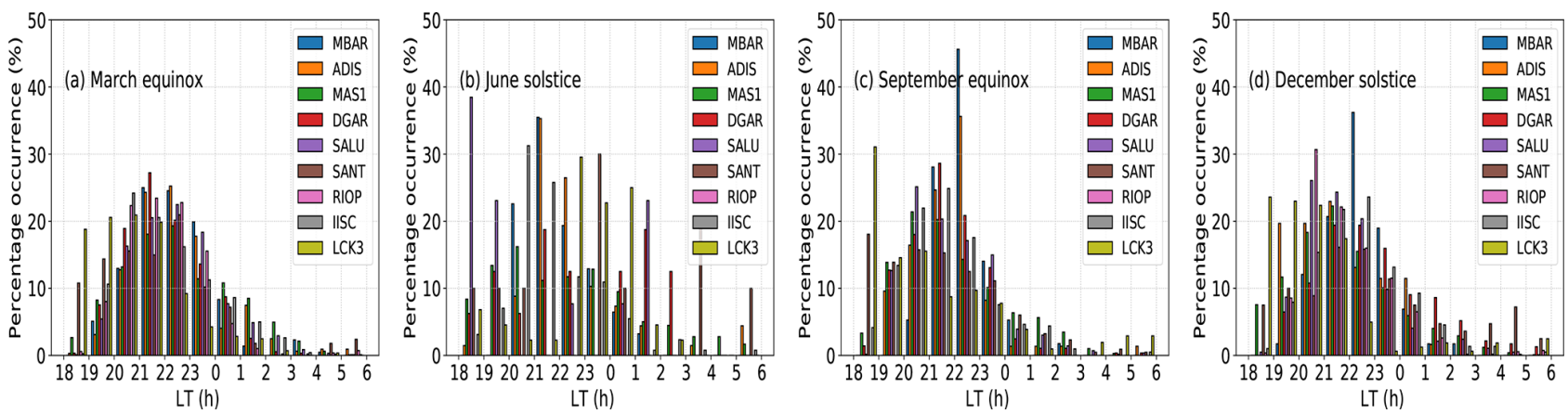

Figure 5. Percentage occurrence of ROTI of $>0.5 \mathrm{TECU} \mathrm{min}^{-1}$ in $1 \mathrm{~h} \mathrm{LT}$ bins for different stations (see legend).

The different seasons are shown in the four panels from top to bottom.

The first noticeable feature in Figs. 6 and 7 is that almost all the irregularities occur within the EIA belts between about \pm 15 and $\pm 20^{\circ}$ of magnetic latitudes. However, Fig. 6 shows that absolute variations of $d N_{\mathrm{e}}$ are observed with a gap of low values at the magnetic equator, while in Fig. 7 maximum values of $d N_{\mathrm{e}} / N_{\mathrm{e}}$ extend from the northern crest to the southern crest, including the magnetic equator. A clear picture of the density variations across the magnetic equator is seen in a scatter plot of the irregularities as a function of latitude as shown in Fig. 8.

Some earlier studies (e.g. Burke et al., 2004; Su et al., 2006, etc.) observed a normal-like distribution that peaks at the quasi-dipole equator and gradually decreases towards higher latitudes, reaching a minimum at around $\pm 30^{\circ}$ QLat, while others observed ionospheric irregularities concentrated around the northern and southern EIA belts (e.g. Liu et al., 2005; Stolle et al., 2006; Carter et al., 2013, etc.). Only a few losses of the GPS tracks have been seen on the quasi-dipole equator (e.g. Buchert et al., 2015; Xiong et al., 2016a; Wan et al., 2018). Consequently, the variations in electron density at the quasi-dipole equator are relatively harmless to the GPS, the high-risk region being the high-density bands, north and south (Buchert et al., 2015).
Furthermore, there are differences between Swarm A together with $\mathrm{C}$ and $\mathrm{B}$ in seasonal and longitudinal irregularity distribution. Swarm B shows the lowest values of both $d N_{\mathrm{e}}$ and $d N_{\mathrm{e}} / N_{\mathrm{e}}$ compared to A and C. A similar observation was made by Zakharenkova et al. (2016) who compared the seasonal and longitudinal variation of ionospheric irregularities only for Swarm A and B during the years 2014-2015 using the $1 \mathrm{~s} N_{\mathrm{e}}$ LP data. The differences observed between Swarm A together with C and Swarm B can be explained by the altitude and local-time separation between the satellites as Swarm B flies at a higher altitude and always crosses the post-sunset sector later than $\mathrm{A}$ and $\mathrm{C}$.

In terms of seasons, high values of $d N_{\mathrm{e}}$ and $d N_{\mathrm{e}} / N_{\mathrm{e}}$ are observed during the equinoxes at all longitudes, especially in the African-Atlantic-South American regions. During the June solstice, moderate values occur mostly in the African sector, and the lowest values occur in the Atlantic-South American sector. During the December solstice, high values are observed in the Atlantic-American sector. From the Indian Ocean to central Pacific sectors, where the magnetic field declination is low, no satellite detected many intense ionospheric irregularities in the solstice seasons and in the September equinox. Overall, the seasonal and longitudinal irregularity distribution shown in Figs. 6 and 7 is consistent with earlier studies irrespective of the criteria adopted (e.g. Su et al., 2006; Huang et al., 2001; Burke et al., 2004; Park 

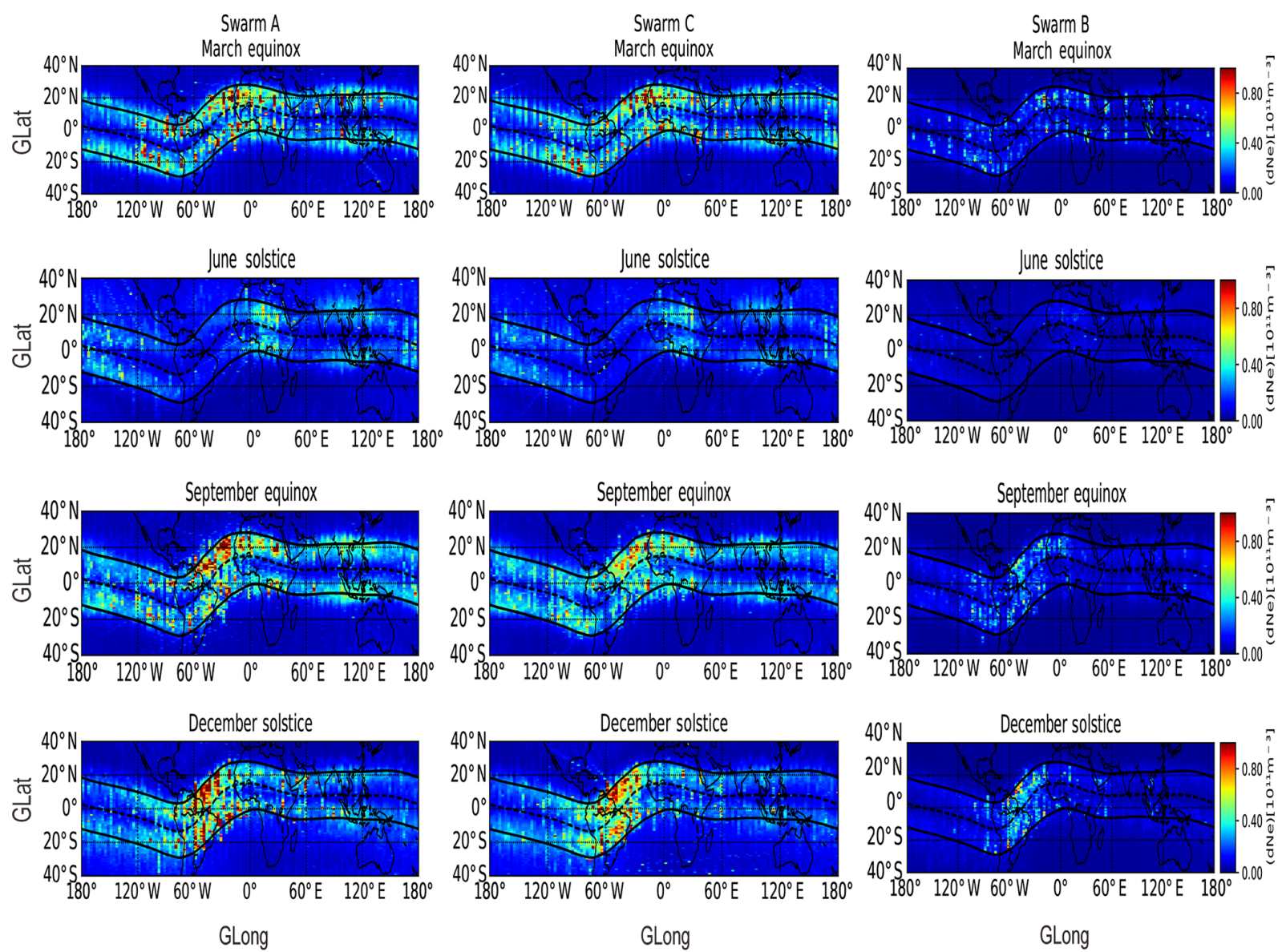

Figure 6. Absolute electron density perturbation $\left(d N_{\mathrm{e}}\right)$ separated into four seasons (March or September equinox and June or December solstice) from October 2014 to October 2018 for Swarm A, C and B. The black dotted line represents the magnetic equator, while the black solid lines represent the EIA belts at about $\pm 15^{\circ}$ of magnetic latitude. For each panel of a season, the colour scales represent $d N_{\mathrm{e}}$.

et al., 2005; Huang et al., 2014; Zakharenkova et al., 2016; Wan et al., 2018). The RTI is known to intensify after sunset, causing severe irregularities when the day-night terminator is aligned with the plane of the magnetic field that occurs in the equinox (Tsunoda, 1985; Burke et al., 2004; Gentile et al., 2006; Yizengaw and Groves, 2018).

One of the challenges has been explaining the mechanism governing the longitudinal distribution of irregularities. Tsunoda (1985) proposed a model based on the magnetic declination to explain the distribution of ionospheric irregularities. However, this model could not explain the high occurrence of irregularities in the June solstice over the African longitude. The longitudinal distribution of irregularities has also been attributed to gravity waves originating from the thermosphere (Yizengaw and Groves, 2018, and references therein). Yizengaw and Groves (2018) also added that the position of the intertropical convergence zone (ITCZ), which is a source of gravity waves, may explain the longitudinal irregularity dependence observed. Kil et al. (2004) suggested that the longitudinal distribution at EIA latitudes of absolute electron density affects the occurrence of irregularities. Us- ing Defense Meteorological Satellite Program (DMSP) data, Huang et al. (2001), Huang et al. (2002), and Burke et al. (2004) showed that the pattern of precipitation of the inner radiation belt's energetic particles explains the pattern of irregularities.

Among other parameters, the growth rate of equatorial ionospheric irregularities is controlled by the electron density gradient. Ionospheric irregularities in the equatorial and low latitudes can cascade upwards and along the magnetic field lines to the EIA belts characterized by high background $N_{\mathrm{e}}$ and steep gradients in density (Muella et al., 2010). From both local-time and longitudinal perspectives, Wan et al. (2018) confirmed that the depletion amplitudes of irregularities are closely linked to the background electron density intensity. Xiong et al. (2016a) concluded that GPS signal reception may be interfered by small-scale plasma density structures with large-density gradients in zonal and meridional directions. Here, we attempt to compare the seasonal and longitudinal distribution of electron density gradient in the meridional direction along the tracks of the Swarm satellites with the magnitudes presented in Figs. 6 and 7. 

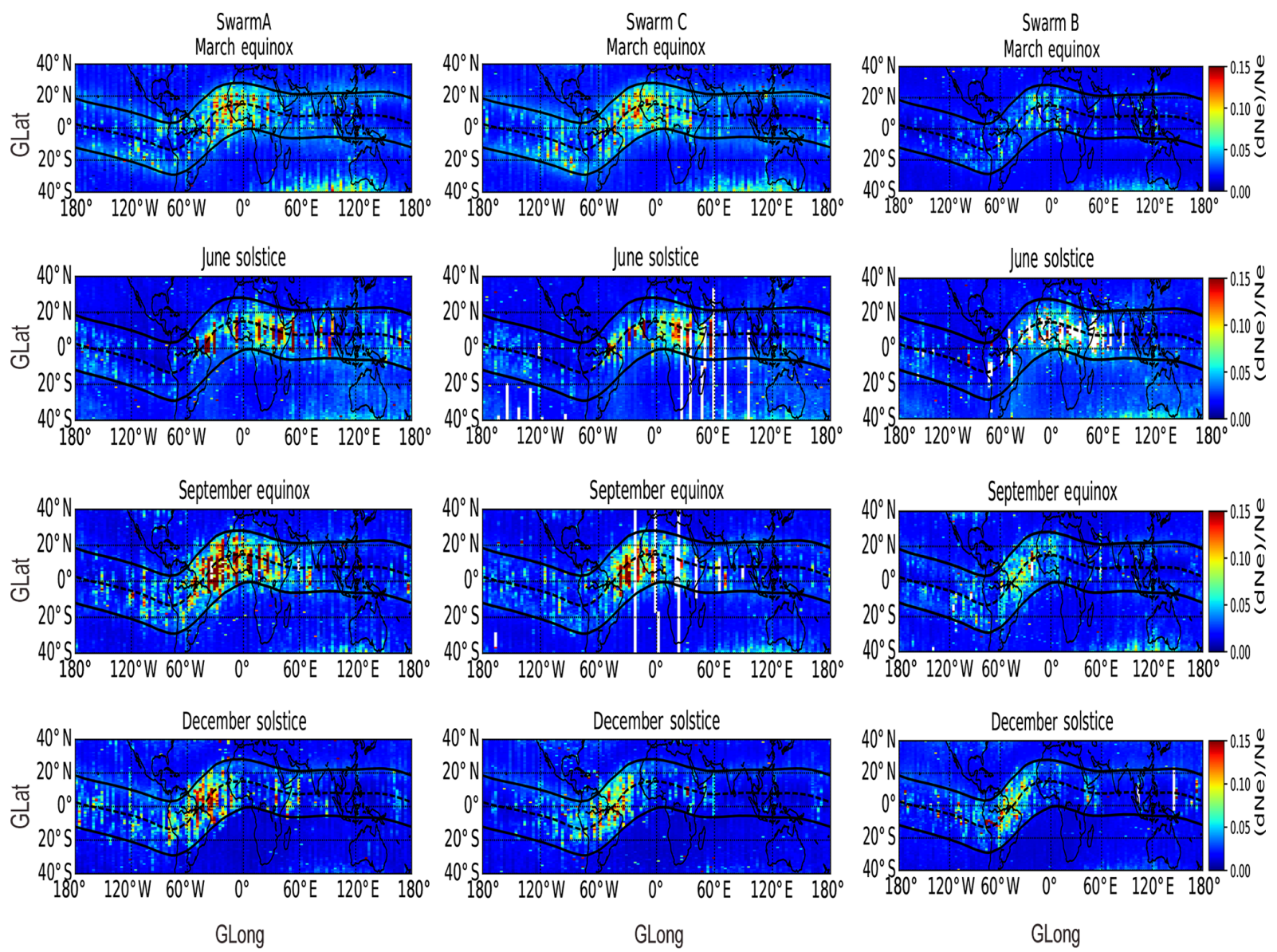

Figure 7. Relative electron density perturbation $\left(d N_{\mathrm{e}} / N_{\mathrm{e}}\right)$ separated into four seasons (March or September equinox and June or December solstice) from October 2014 to October 2018 for Swarm A, C and B. The black dotted line represents the magnetic equator, while the black solid lines represent the EIA belts at about $\pm 15^{\circ}$ of magnetic latitude. For each panel of a season, the colour scales represent $d N_{\mathrm{e}} / N_{\mathrm{e}}$.

To determine the $N_{\mathrm{e}}$ gradient along the satellite tracks, $N_{\mathrm{e}}$ depletion was divided by the corresponding latitudinal distance in degrees. Figure 9 presents the $N_{\mathrm{e}}$ gradient $\nabla N_{\mathrm{e}}$ classified in different seasons for Swarm A, C and B, independently. The seasonal and longitudinal distribution of $\nabla N_{\mathrm{e}}$ generally shows the same pattern as that of $d N e$ and $d N_{\mathrm{e}} / N_{\mathrm{e}}$ with high values observed during the equinoxes and December solstice and moderate values in the African sector in the June solstice. However, close inspection of Fig. 9 shows that the $\nabla N_{\mathrm{e}}$ has the same latitudinal distribution as $d N_{\mathrm{e}}$; i.e. it is symmetrical about the magnetic equator with high values at the EIA belts. On the other hand, the latitudinal distribution of $\nabla N_{\mathrm{e}}$ is different from that of $d N_{\mathrm{e}} / N_{\mathrm{e}}$ (see Fig. 7). Earlier studies have also shown that irregularity events at latitudes of the EIA might be associated with the regions of a strong density gradient (e.g. Basu et al., 2001; Keskinen et al., 2003; Muella et al., 2008). The formation of small-scale irregularities appears to be more likely in ionospheric regions with higher background electron density and steep electron density gradients (Keskinen et al., 2003; Muella et al., 2008, 2010). Therefore, the amplitudes of ionospheric irregularities closely depend on background electron density (Wan et al., 2018) and steep $N_{\mathrm{e}}$ gradient globally as expected.

\subsection{Magnetic- and solar-activity dependence of ionospheric irregularities}

The Swarm faceplate observations began the near solar maximum in October 2014 and approached the solar minimum of solar cycle 24 towards the end of 2018. Figure 10 shows the $\mathrm{Kp}$ index and $10.7 \mathrm{~cm}$ solar radio flux (F10.7) index in units of $10^{-22} \mathrm{Wm}^{-2} \mathrm{~Hz}^{-1}$ to summarize the magnetic and solar activity for the period 2014-2018.

In general, solar cycle 24 was characterized by very low solar activity compared to cycles that preceded it (Basu, 2013). The F10.7 varied often between about 50 and $200 \mathrm{sfu}$ (solar flux unit) for the period 2014-2018. This period was also characterized by geomagnetic storms with $\mathrm{Kp}$ values of $>3$. The effects of geomagnetic disturbances and changes in solar activity on ionospheric irregularity characteristics are of scientific interest and have been investigated in multiple studies (e.g. Palmroth et al., 2000; Sobral et al., 2002; Huang 

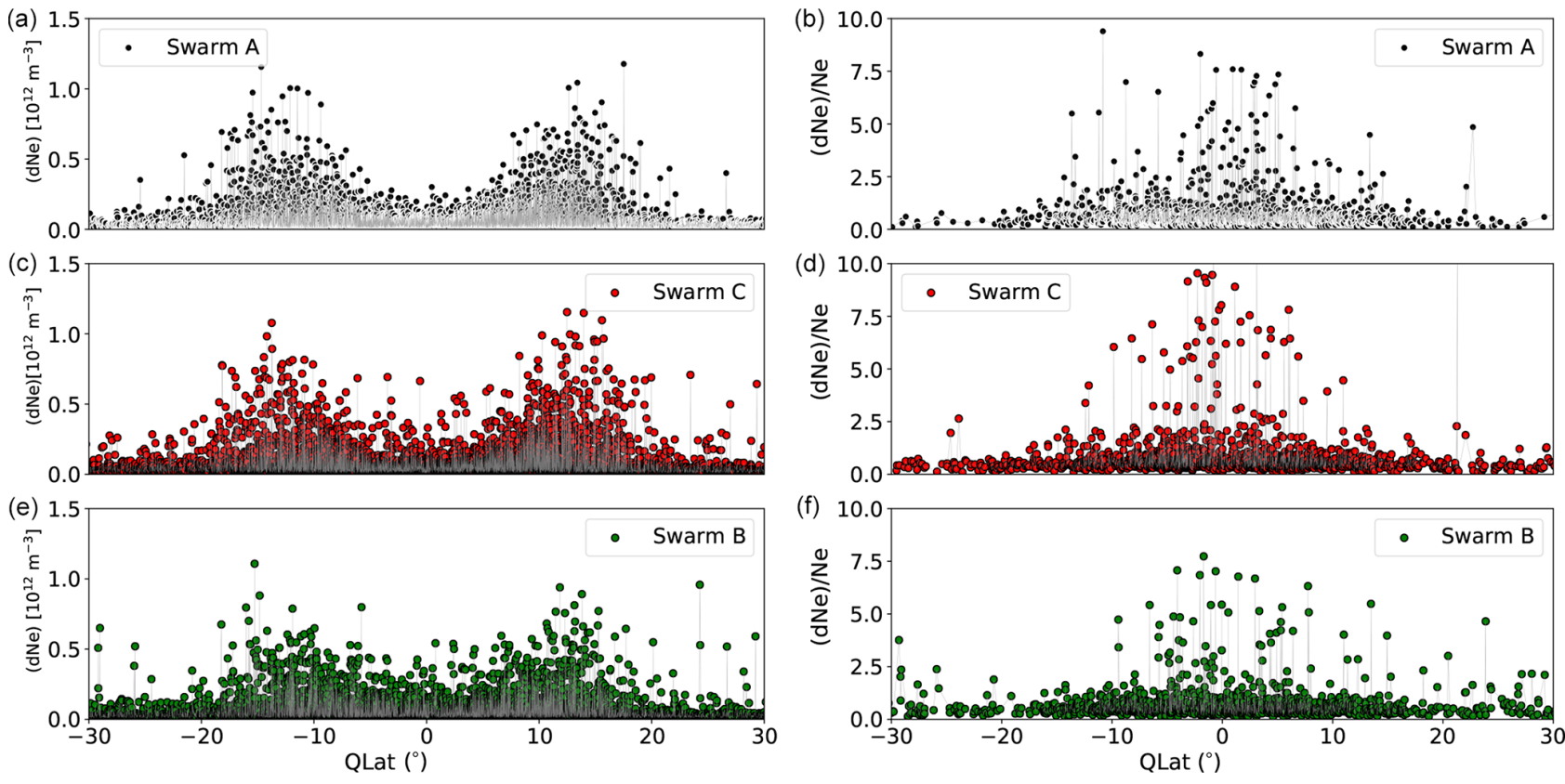

Figure 8. Scatter plots of the latitude distribution of ionospheric irregularities observed for the period from October 2014 to October 2018. The left panel shows the distribution when irregularities are quantified using $d N_{\mathrm{e}}$, while the right panel shows the distribution when $d N_{\mathrm{e}} / N_{\mathrm{e}}$ is used.

et al., 2002, 2014; Gentile et al., 2006; Stolle et al., 2006; Nishioka et al., 2008; Li et al., 2009; Basu et al., 2010; Sun et al., 2012; Carter et al., 2013). By using different criteria, Huang et al. (2014) determined the solar activity dependence of the occurrence of irregularities. In addition to solar activity, we also used different criteria to check the effects of magnetic variability on the distribution characteristics of irregularities in low latitudes.

Scatter plots of $d N_{\mathrm{e}}$ in Fig. 11a and $d N_{\mathrm{e}} / N_{\mathrm{e}}$ in Fig. $11 \mathrm{~b}$ as functions of F10.7 are shown for Swarm A, B and C, independently. To check on the solar activity dependence of $d N_{\mathrm{e}}$ and $d N_{\mathrm{e}} / N_{\mathrm{e}}$ at the Equator and the EIA belts, the Swarm satellite passes were divided into three latitudinal ranges, i.e. Equator $\left( \pm 5^{\circ}\right.$ quasi-dipole latitude), the southern EIA region ( -30 to $-5^{\circ}$ quasi-dipole latitude) and the northern EIA region $\left(+5\right.$ to $+30^{\circ}$ quasi-dipole latitude) (see legend of Fig. 11).

Each panel of Fig. 11 contains linear fits and the correlation coefficients $R$. In general, both $d N_{\mathrm{e}}$ and $d N_{\mathrm{e}} / N_{\mathrm{e}}$ show a weak positive correlation with F10.7 irrespective of the latitudinal range, and this may be attributed to the small data set used. However, it can be seen that the correlation between F10.7 and $d N_{\mathrm{e}}$ is higher at the EIA regions than at the Equator. This also shows the symmetrical distribution of $d N_{\mathrm{e}}$ with higher values obtained at the EIA belts than at the Equator. There is hardly any difference observed between equatorial and off-equatorial latitudes for the case of $d N_{\mathrm{e}} / N_{\mathrm{e}}$. The results obtained for $d N_{\mathrm{e}}$ is consistent with that of Liu et al.
(2007) who presented the solar activity dependence of the electron density at the equatorial anomaly regions.

For Swarm A alone, Fig. 12 shows the solar variation effect on the seasonal and longitudinal distribution of $d N_{\mathrm{e}}$ and $d N_{\mathrm{e}} / N_{\mathrm{e}}$.

The results are divided into two major columns (distribution with respect to $d N_{\mathrm{e}}$ to the left and $d N_{\mathrm{e}} / N_{\mathrm{e}}$ to the right). In each major column, there are two sub-columns, one for low solar activity $(\mathrm{F} 10.7<140)$ and the other for moderate solar activity $(140 \leqq \mathrm{~F} 10.7<180)$. It is important to point out that a reduced number of days were used to generate the climatology maps when $140 \leqq \mathrm{~F} 10.7<180$ compared to when F10.7 < 140. In Fig. 12, high $d N_{\mathrm{e}}$ values are often observed when $140 \leqq \mathrm{~F} 10.7<180$. On the contrary, high values of $d N_{\mathrm{e}} / N_{\mathrm{e}}$ are mostly observed when F10.7 $<140$. The F10.7 dependence obtained using $d N_{\mathrm{e}}$ is similar to the results presented by Huang et al. (2001), Su et al. (2006), and Stolle et al. (2006). It is necessary to note that Huang et al. (2001), Su et al. (2006), and Stolle et al. (2006) addressed the solar activity dependence of the occurrence rate of ionospheric irregularities. Wan et al. (2018) presented differences between the occurrence rate of ionospheric irregularities and their amplitudes in terms of the latitudinal and longitudinal distribution. However, in general, the seasonal and longitudinal distribution of $d N_{\mathrm{e}}$ presented in Fig. 12 shows a similar dependence on different levels of F10.7 as the occurrence rates. Using simulations from the MagnetosphereThermosphere-Ionosphere-Electrodynamics General Circulation Model (MTIEGCM), Vichare and Richmond (2005) 

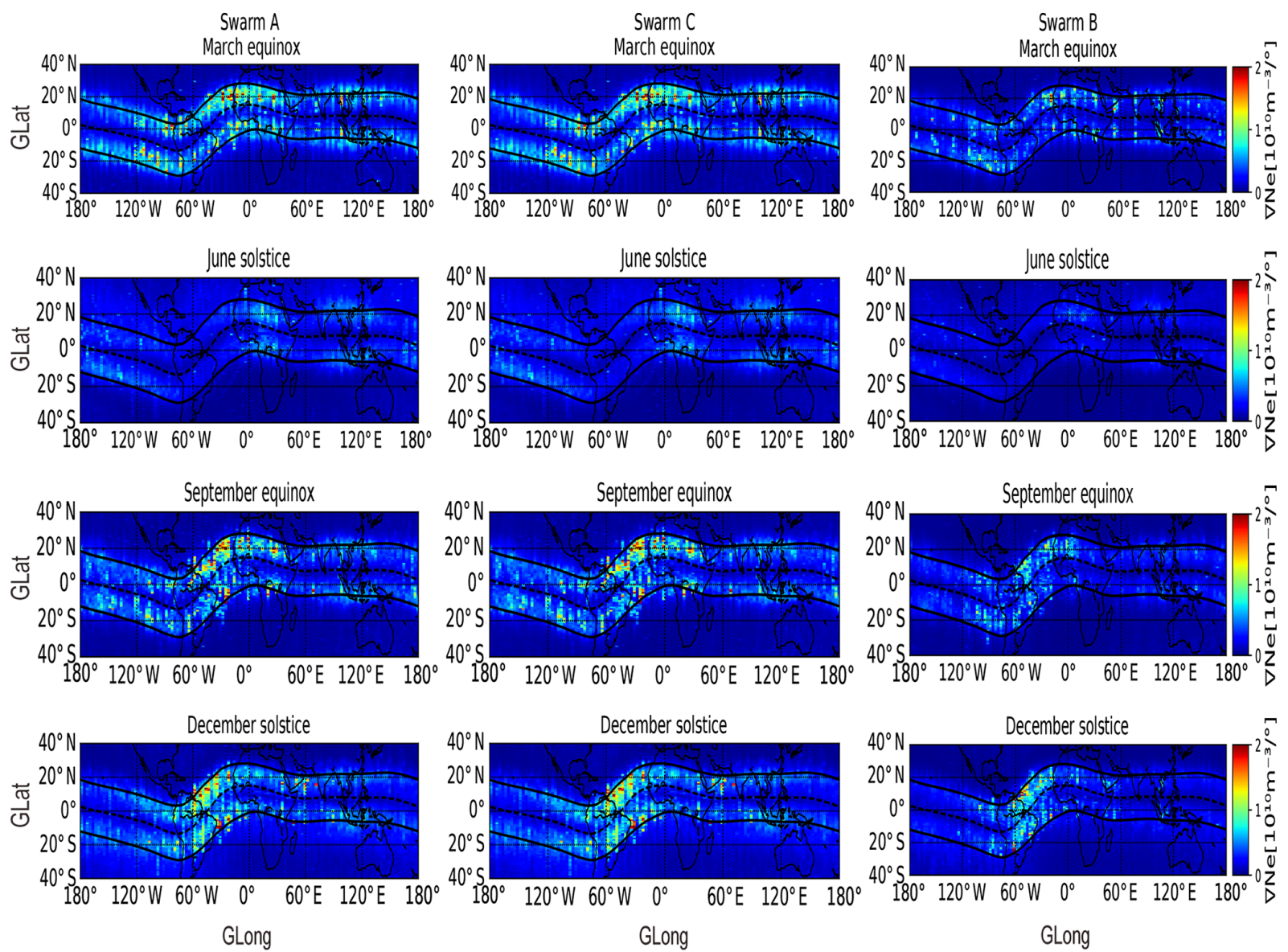

Figure 9. Along-track electron density gradient $\nabla N_{\mathrm{e}}$ as derived from the Swarm satellites separated into four seasons (March or September equinox and June or December solstice) from October 2014 to October 2018 for Swarm A, C and B. The black dotted line represents the magnetic equator, while the black solid lines represent the EIA belts at about $\pm 15^{\circ}$ of magnetic latitude.

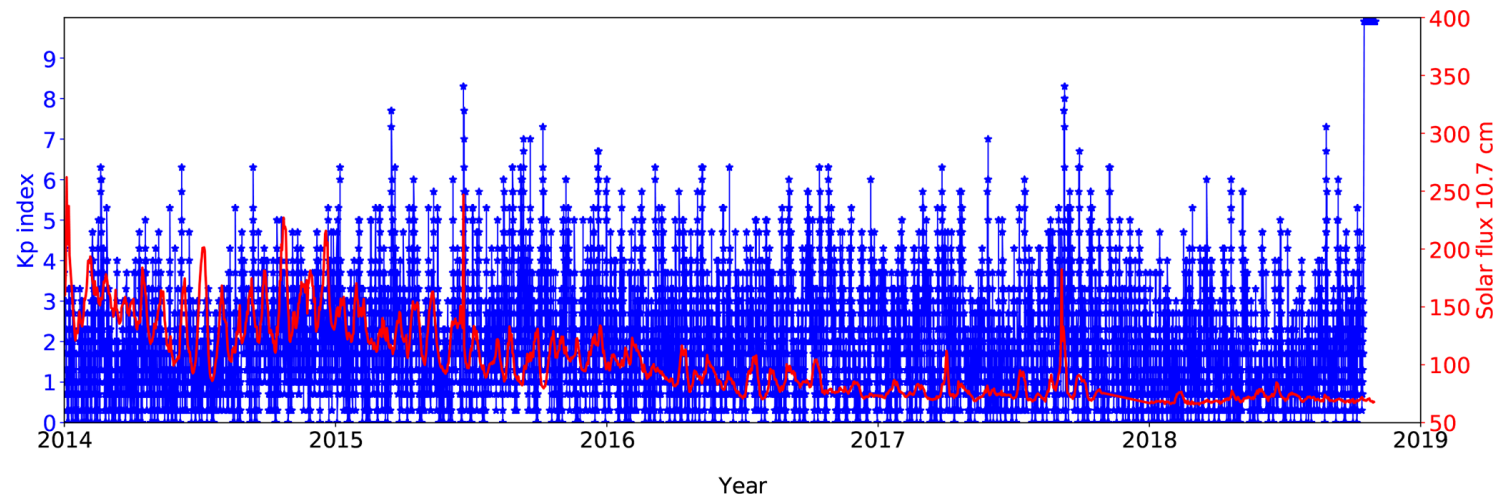

Figure 10. The $10.7 \mathrm{~cm}$ solar radio flux in solar flux units and the Kp index during 2014-2018.

showed that upward evening drift increases at a similar rate in all longitude sectors with solar activity. Therefore, the high occurrence of irregularities during a period of moderate or high solar activity may be because of the atmospheric driver for the zonal electric field which intensifies during moderate or high solar activity, causing an increase in the RTI growth rate.

Figure 13 presents scatter plots of $d N_{\mathrm{e}}$ in Fig. 13a and $d N_{\mathrm{e}} / N_{\mathrm{e}}$ in Fig. 13b as functions of Kp. To generate Fig. 13, the Swarm passes were also split into equatorial and EIA latitudes, similar to Fig. 11. 
(a) $\left(d N_{e}\right)$
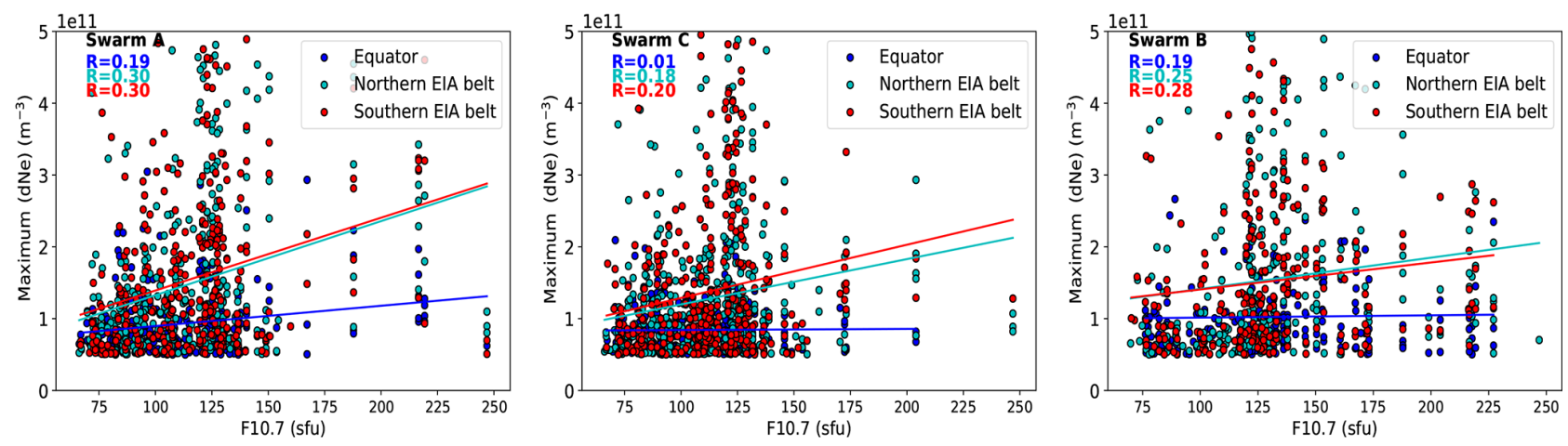

(b) $\left(d N_{e}\right) / N_{e}$
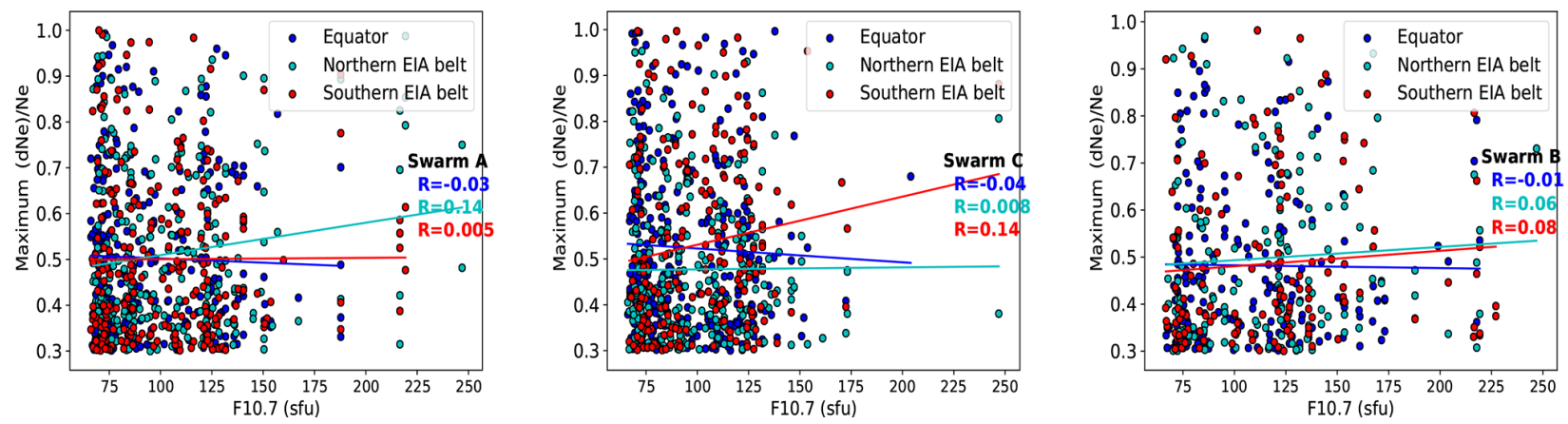

Figure 11. The distribution characteristics of (a) $d N_{\mathrm{e}}$ and (b) $d N_{\mathrm{e}} / N_{\mathrm{e}}$ with respect to $10.7 \mathrm{~cm}$ solar radio flux in solar flux units for the period from October 2014 to October 2018. The coloured solid lines in each panel represent a linear fit to the data.

In general, the results show a weak correlation with $\mathrm{Kp}$ values close to zero, irrespective of the method used to quantify the level of equatorial ionospheric irregularities and the latitude range. Close inspection of Fig. 13 shows that the correlation between $d N_{\mathrm{e}}$ and $\mathrm{Kp}$ was lowest at the EIA belts compared to that at the Equator. There is hardly any difference observed between equatorial and off-equatorial latitudes for the case of $d N_{\mathrm{e}} / N_{\mathrm{e}}$. Dao et al. (2011) adopted the relative perturbation to quantify irregularities. Their reason for using the relative perturbation was that the absolute perturbation is correlated with the ambient ion density, which varies due to several factors such as varying altitude. The results shown in Figs. 11 and 13 also show that $d N_{\mathrm{e}}$ is more sensitive to solar and magnetic variations compared to $d N_{\mathrm{e}} / N_{\mathrm{e}}$. The differences in the correlation between F10.7 or Kp and $d N_{\mathrm{e}}$ or $d N_{\mathrm{e}} / N_{\mathrm{e}}$ at equatorial and off-equatorial latitudes can be explained by the differences in background electron density and electron density gradients at the crests and trough. Using DMSP pre-midnight plasma data, Huang et al. (2001) found that the rates of occurrence of irregularity and geomagnetic activity were negatively correlated. We also examined the geomagnetic effect on the seasonal and longitudinal distribution of irregularities as presented in Fig. 14 for Swarm A.
The results are divided into two major columns (distribution with respect to $d N_{\mathrm{e}}$ to the left and $d N_{\mathrm{e}} / N_{\mathrm{e}}$ to the right). In each major column, there are two sub-segments, one for calm geomagnetic occasions $(\mathrm{Kp}<3)$ and the other for geomagnetically disturbed periods ( $\mathrm{Kp} \geqq 3$ ). From Fig. 14, high values of both $d N_{\mathrm{e}}$ and $d N_{\mathrm{e}} / N_{\mathrm{e}}$ are frequently observed when $\mathrm{Kp}<3$. Palmroth et al. (2000) found a negative correlation between $\mathrm{Kp}$ and pre-midnight plasma depletions and a positive post-midnight correlation. They linked the distinction before and after local midnight to electrical fields disturbed westward and eastward, respectively. Stolle et al. (2006) checked the response of the occurrence of ionospheric irregularities to geomagnetic activity using magnetic field measurements made by CHAMP, and they observed a weak relation between the occurrence of irregularities and the Kp index. Huang et al. (2001) also used DMSP measurements of plasma density and found that the occurrence rate of ionospheric irregularities for low $\mathrm{Kp}$ values were almost doubled compared to when Kp values are high. The geomagnetic activity affects irregularity occurrence in the low latitudes in two noteworthy ways, i.e. by the brief entrance of auroral electric fields (Fejer, 1991; Kikuchi et al., 1996) and by the unsettling influence of dynamo effects (Blanc and Richmond, 1980). The second mechanism produces disturbance electric 

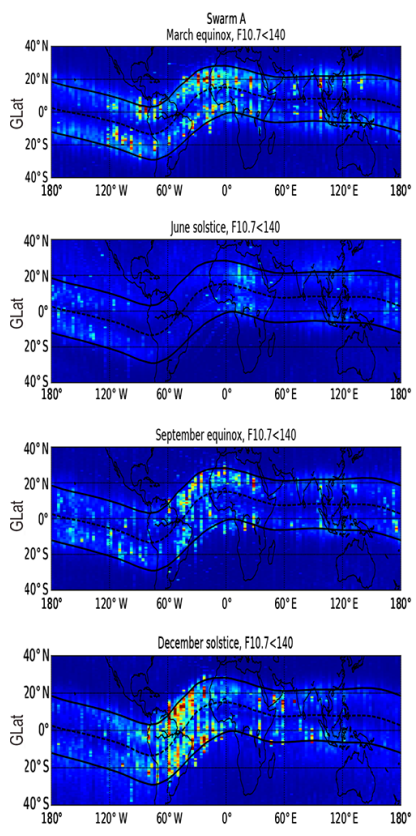

GLong

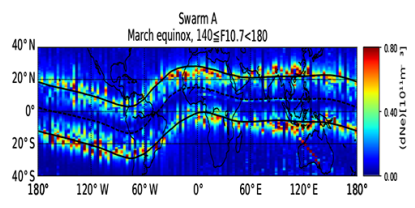

June solstice, 140 $5110.7<180$
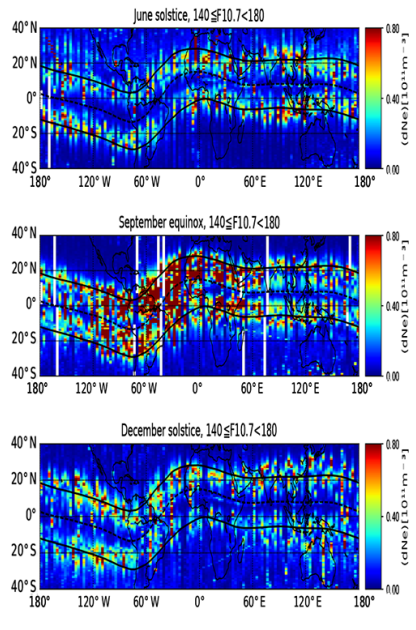

GLong

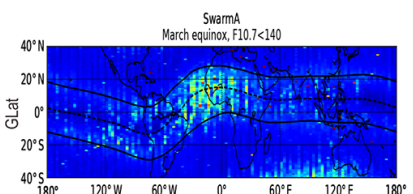

June solstice, F10.7<140
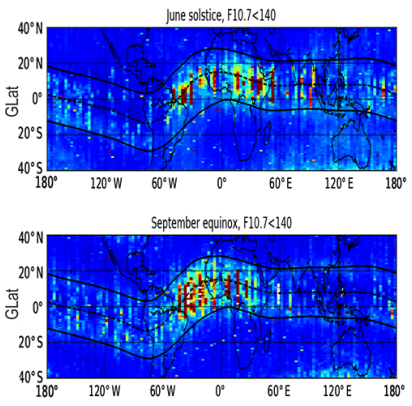

December solstice, F10.7<140

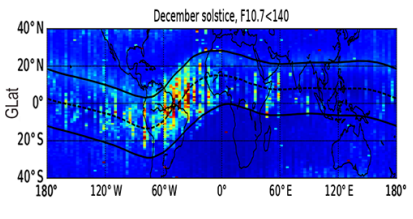

GLong
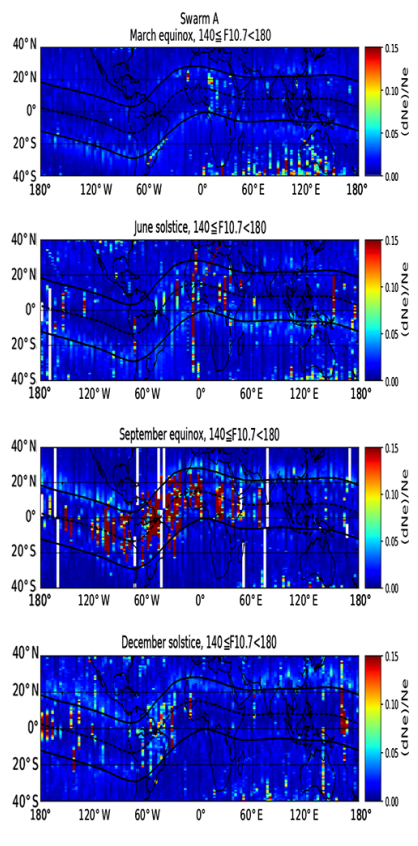

GLong

Figure 12. Solar activity effect on seasonal and longitudinal distribution of $d N_{\mathrm{e}}$ and $d N_{\mathrm{e}} / N_{\mathrm{e}}$ for the period from October 2014 to October 2018: a case for Swarm A.

(a) $\left(d N_{e}\right)$
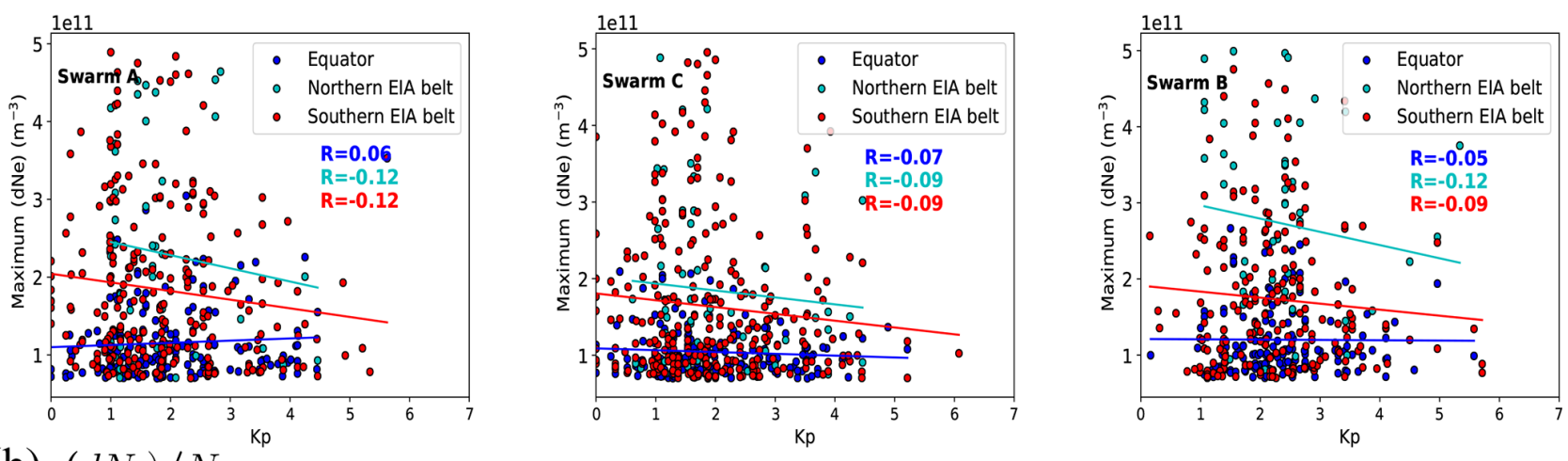

(b) $\left(d N_{e}\right) / N_{e}$
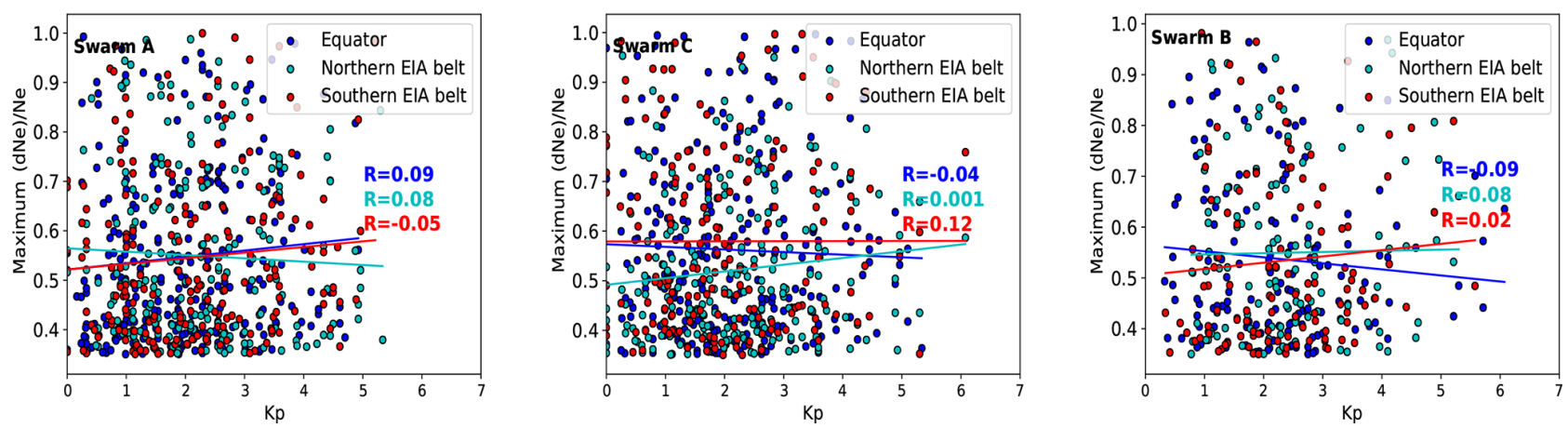

Figure 13. The distribution characteristics of (a) $d N_{\mathrm{e}}$ and (b) $d N_{\mathrm{e}} / N_{\mathrm{e}}$ with respect to the Kp index for the period from October 2014 to October 2018. The coloured solid lines in each panel represent a linear fit to the data. 

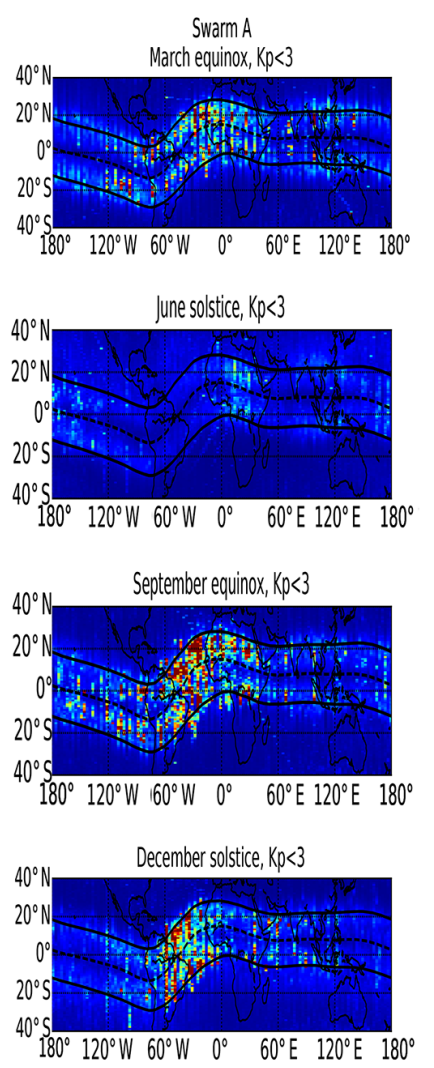

GLong
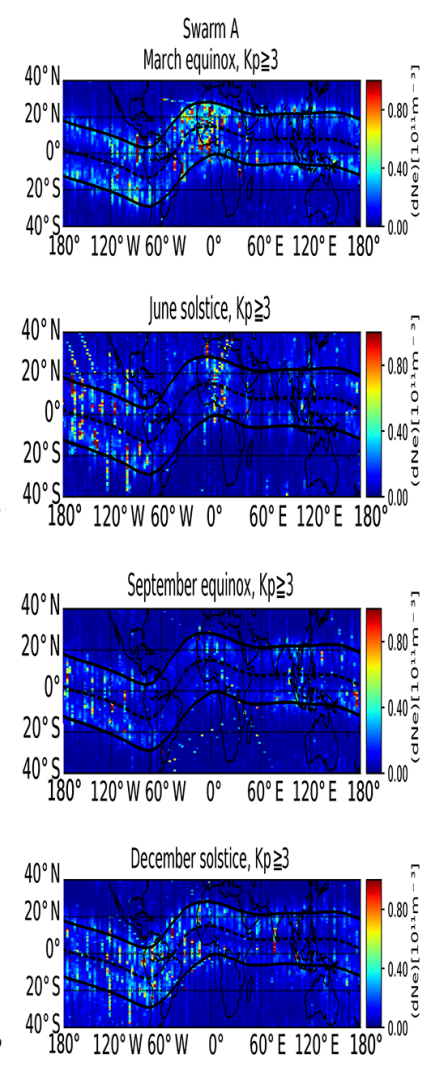

GLong
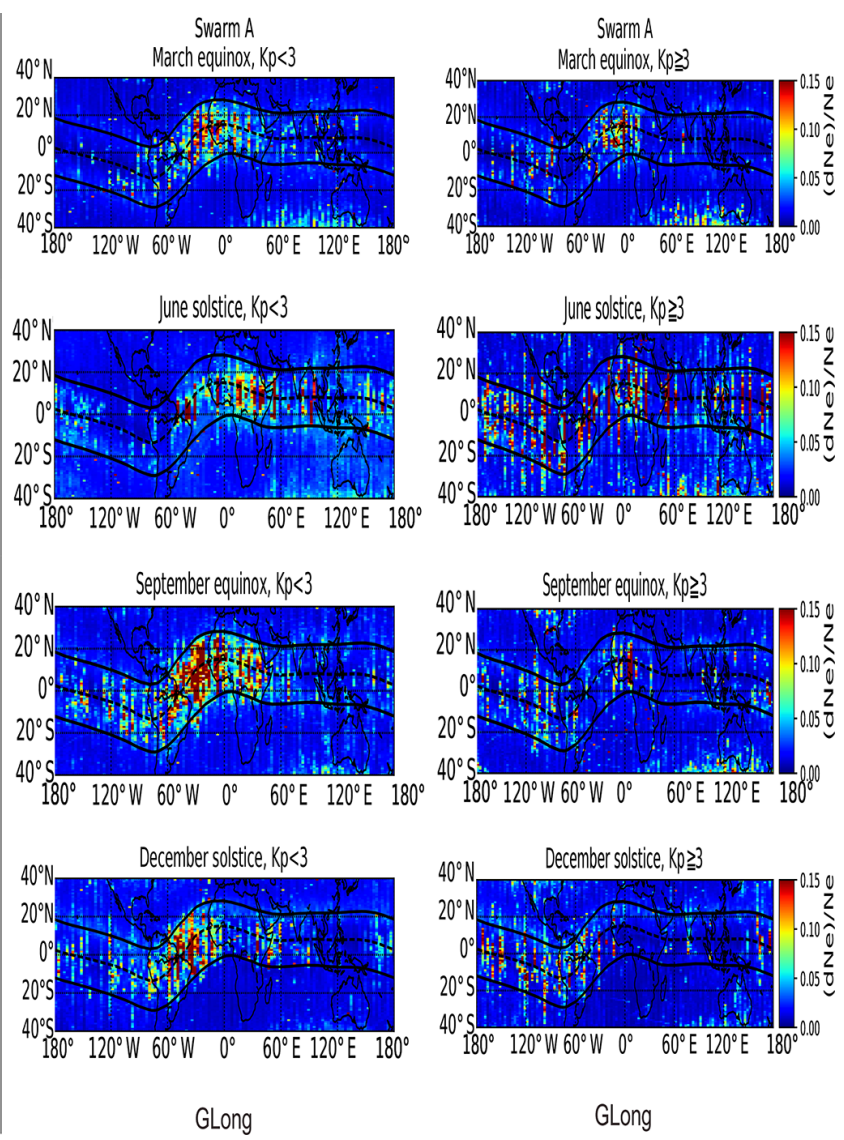

Figure 14. Geomagnetic effect on seasonal and longitudinal distribution of $d N_{\mathrm{e}}$ and $d N_{\mathrm{e}} / N_{\mathrm{e}}$ for the period from October 2014 to October 2018: a case for Swarm A.

fields which last for a long time. The disturbance electric fields are westward after sunset (Blanc and Richmond, 1980; Huang et al., 2005; Abdu, 2012). It is important to note that the well-known trend in the longitudinal distribution of $d N_{\mathrm{e}}$ and $d N_{\mathrm{e}} / N_{\mathrm{e}}$ for some seasons may not be clearly observed in Figs. 12 and 14 because of limited data after categorizing with respect to Kp or F10.7.

\section{Conclusions}

In this study, we have used Swarm $N_{\mathrm{e}}$ data measured by the faceplate at a frequency of $16 \mathrm{~Hz}$ to examine the distribution characteristics of ionospheric irregularities in the equatorial and low-latitude ionosphere from 2014 to 2018 when the $16 \mathrm{~Hz}$ data were available. Two methods (absolute and relative perturbation) were used to quantify the level of ionospheric irregularities. Both methods were able to capture fluctuations in electron density along single satellite passes. Basing on the large number of Swarm low-latitude crossings for the years 2014-2018, the local-time, seasonal and longitudinal distribution of ionospheric irregularities in the low latitudes were examined. We demonstrated the importance of steep density gradients for the generation and distribu- tion of ionospheric irregularities in the low latitudes. We also checked the effects of geomagnetic and solar activity on the distribution characteristics of ionospheric irregularities. The findings are summarized below:

i. The local-time distribution of irregularities quantified by the two methods showed that they are mainly nighttime phenomena as expected. Both $d N_{\mathrm{e}}$ and $d N_{\mathrm{e}} / N_{\mathrm{e}}$ showed similar trends in percentage occurrence during the equinoxes and December solstice with a peak occurrence between 20:00 and 22:00 LT. The percentage occurrence was lowest in the June solstice. Generally, the local-time dependence of ionospheric irregularities is not much different when either $d N_{\mathrm{e}}$ or $d N_{\mathrm{e}} / N_{\mathrm{e}}$ is used. However, the local-time distribution according to $d N_{\mathrm{e}}$ is closely related to that of ROTI derived from groundbased stations.

ii. In general, the seasonal and longitudinal distribution of ionospheric irregularities as quantified by the Swarm $16 \mathrm{~Hz} N_{\mathrm{e}}$ data was in agreement with past observations using other satellite missions irrespective of the method used. However, close inspection of the magnetic latitudes reveals that $d N_{\mathrm{e}}$ and $d N_{\mathrm{e}} / N_{\mathrm{e}}$ showed different lat- 
itudinal distribution of ionospheric irregularities about the magnetic equator. The $d N_{\mathrm{e}}$ showed a symmetric distribution about the magnetic equator with high magnitudes at latitudes of about $\pm 10- \pm 15^{\circ}$. The $d N_{\mathrm{e}} / N_{\mathrm{e}}$ showed a peak at the quasi-dipole equator which gradually decreased towards higher latitudes.

iii. The seasonal and longitudinal distribution of electron density gradient was closely related to that of $d N_{\mathrm{e}}$ and $d N_{\mathrm{e}} / N_{\mathrm{e}}$. Also, symmetry about the magnetic equator was observed with $\nabla N_{\mathrm{e}}$. Therefore, in addition to the background electron density presented by Wan et al. (2018), the longitudinal distributions of ionospheric irregularities also depends on steep electron density gradients as expected.

iv. The $d N_{\mathrm{e}}$ showed a weak positive correlation with F10.7, and the correlation was even lower with $d N_{\mathrm{e}} / N_{\mathrm{e}}$. Furthermore, $d N_{\mathrm{e}}$ in the EIA crest regions grew approximately linearly from low to moderate solar activity, with a higher correlation than that in the EIA trough region. The F10.7 dependence of the seasonal and longitudinal distribution of the ionospheric irregularities showed slightly different trends between $d N_{\mathrm{e}}$ and $d N_{\mathrm{e}} / N_{\mathrm{e}}$. The discrepancy between the two methods may be because of the limited data. In general, the distribution of ionospheric irregularities was still lower during the geomagnetically disturbed period than in quiet times. The correlation between $d N_{\mathrm{e}}$ and $\mathrm{Kp}$ was lowest at the EIA belts compared to that at the Equator. The solar and magnetic activity dependence of $d N_{\mathrm{e}} / N_{\mathrm{e}}$ hardly showed any difference in correlation between equatorial and offequatorial latitudes.

Despite the obvious limitations of using polar-orbiting satellites to monitor equatorial electrodynamics, Swarm has provided credible distribution characteristics of ionospheric irregularities in the low-latitude region with data accumulated for 5 years (2014-2018). In general, the initial observations of the distribution characteristics of ionospheric irregularities using the $16 \mathrm{~Hz} N_{\mathrm{e}}$ data are in good agreement with earlier works that have addressed similar concepts. This has demonstrated the ability of Swarm faceplate $N_{\mathrm{e}}$ data for ionospheric studies. Therefore, the $16 \mathrm{~Hz}$ faceplate data are a useful measurement that can be adopted in order to understand ionospheric irregularities.

Data availability. The official website of Swarm is http://earth.esa.int/swarm (last access: 14 February 2020), and ftp://swarm-diss.eo.esa.int/Advanced/Plasma_Data/16_Hz_ Faceplate_plasma_density/ (last access: 13 February 2020) is the server for the distribution of Swarm data. IGS and GPS data for the equatorial and low-latitude stations were downloaded from ftp://garner.ucsd.edu/pub/rinex/ (last access: 12 February 2020). The Kp index and F10.7 solar radio flux data used in this study were obtained from the website https://cdaweb.gsfc.nasa.gov/index.html/ (last access: 31 December 2019).

Author contributions. AS, SB and EJ designed the concepts and implemented them. AS prepared the paper with contributions from all co-authors.

Competing interests. The authors declare that they have no conflict of interest.

Acknowledgements. This study was sponsored by the International Science Programme (ISP) of Uppsala University, Sweden. The authors acknowledge the ESA Swarm team for the Swarm mission and for providing the Swarm data.

Financial support. This research has been supported by the International Science Programme (ISP).

Review statement. This paper was edited by Petr Pisoft and reviewed by five anonymous referees.

\section{References}

Abdu, M.: Equatorial spread F/plasma bubble irregularities under storm time disturbance electric fields, J. Atmos. Sol.-Terr. Phys., 75/76, 44-56, https://doi.org/10.1016/j.jastp.2011.04.024, 2012.

Abdu, M. A.: Equatorial ionosphere thermosphere system: Electrodynamics and irregularities, Adv. Space Res., 35, 771-787, https://doi.org/10.1016/j.asr.2005.03.150, 2005.

Basu, S.: The peculiar solar cycle 24 - where do we stand?, J. Phys. Conf. Ser., 440, 012001, https://doi.org/10.1088/17426596/440/1/012001, 2013.

Basu, S., Basu, S., and Khan, B. K.: Model of equatorial scintillations from in-situ measurements, Rad. Sci., 11, 821-832, https://doi.org/10.1029/rs011i010p00821, 1976.

Basu, S., Groves, K. M., Quinn, J. M., and Doherty, P.: A comparison of TEC fluctuations and scintillations at Ascension Island, J. Atmos. Sol.-Terr. Phys., 61, 1219-1226, https://doi.org/10.1016/S1364-6826(99)00052-8, 1999.

Basu, S., Basu, S., Valladares, C. E., Yeh, H.-C., Su, S.-Y., MacKenzie, E., Sultan, P. J., Aarons, J., Rich, F. J., Doherty, P., Groves, K. M., and Bullett, T. W.: Ionospheric effects of major magnetic storms during the International Space Weather Period of September and October 1999: GPS observations, VHF/UHF scintillations, and in situ density structures at middle and equatorial latitudes, J. Geophys. Res.-Space, 106, 30389-30413, https://doi.org/10.1029/2001ja001116, 2001.

Basu, S., Basu, S., MacKenzie, E., Bridgwood, C., Valladares, C. E., Groves, K. M., and Carrano, C.: Specification of the occurrence of equatorial ionospheric scintillations during the main phase of large magnetic storms within solar cycle 23, Radio Sci., 45, RS5009, https://doi.org/10.1029/2009RS004343, 2010. 
Bhattacharyya, A., Groves, K. M., Basu, S., Kuenzler, H., Valladares, C. E., and Sheehan, R.: L-band scintillation activity and space-time structure of low-latitude UHF scintillations, Radio Sci., 38, 4-1-4-9, https://doi.org/10.1029/2002rs002711, 2003.

Blanc, M. and Richmond, A.: The ionospheric disturbance dynamo, J. Geophys. Res.-Space, 85, 1669-1686, https://doi.org/10.1029/ja085ia04p01669, 1980.

Buchert, S.: Extended EFI LP data FP release notes, ESA Technical Note, available at: ftp://swarm-diss.eo.esa.int/Advanced/ Plasma_Data/16_Hz_Faceplate_plasma_density (last access: 14 February 2020), 2016.

Buchert, S., Zangerl, F., Sust, M., André, M., Eriksson, A., Wahlund, J.-E., and Opgenoorth, H.: SWARM observations of equatorial electron densities and topside GPS track losses, Geophys. Res. Lett., 42, 2088-2092, https://doi.org/10.1002/2015GL063121, 2015.

Burke, W. J., Huang, C. Y., Valladares, C. E., Machuzak, J. S., Gentile, L. C., and Sultan, P. J.: Multipoint observations of equatorial plasma bubbles, J. Geophys. Res.-Space, 108, 1221, https://doi.org/10.1029/2002JA009382, 2003.

Burke, W. J., Gentile, L. C., Huang, C. Y., Valladares, C. E., and Su, S. Y.: Longitudinal variability of equatorial plasma bubbles observed by DMSP and ROCSAT-1, J. Geophys. Res.-Space, 109, A12301, https://doi.org/10.1029/2004JA010583, 2004.

Carter, B. A., Zhang, K., Norman, R., Kumar, V. V., and Kumar, S.: On the occurrence of equatorial F-region irregularities during solar minimum using radio occultation measurements, J. Geophys. Res.-Space, 118, 892-904, https://doi.org/10.1002/jgra.50089, 2013

Chartier, A. T., Mitchell, C. N., and Miller, E. S.: Annual Occurrence Rates of Ionospheric Polar Cap Patches Observed Using Swarm, J. Geophys. Res.-Space, 123, 2327-2335, https://doi.org/10.1002/2017ja024811, 2018.

Costa, E., Roddy, P. A., and Ballenthin, J. O.: Statistical analysis of C/NOFS planar Langmuir probe data, Ann. Geophys., 32, 773 791, https://doi.org/10.5194/angeo-32-773-2014, 2014

Dao, E., Kelley, M. C., Roddy, P., Retterer, J., Ballenthin, J. O., de La Beaujardiere, O., and Su, Y.-J.: Longitudinal and seasonal dependence of nighttime equatorial plasma density irregularities during solar minimum detected on the C/NOFS satellite, Geophys. Res. Lett., 38, L10104, https://doi.org/10.1029/2011GL047046, 110104, 2011.

Fejer, B. G.: Low latitude electrodynamic plasma drifts: A review, J. Atmos. Terr. Phys., 53, 677-693, https://doi.org/10.1016/00219169(91)90121-m, 1991.

Fejer, B. G., Scherliess, L., and de Paula, E. R.: Effects of the vertical plasma drift velocity on the generation and evolution of equatorial spreadF, J. Geophys. Res.-Space, 104, 19859-19869, https://doi.org/10.1029/1999ja900271, 1999.

Gentile, L. C., Burke, W. J., and Rich, F. J.: A climatology of equatorial plasma bubbles from DMSP 1989-2004, Radio Sci., 41, 1-7, https://doi.org/10.1029/2005RS003340, rS5S21, 2006.

Huang, C., Burke, W., Machuzak, J., Gentile, L., and Sultan, P.: Equatorial plasma bubbles observed by DMSP satellites during a full solar cycle: Toward a global climatology, J. Geophys. Res.Space, 107, 1434, https://doi.org/10.1029/2002ja009452, 2002.

Huang, C.-M., Richmond, A., and Chen, M.-Q.: Theoretical effects of geomagnetic activity on low-latitude iono- spheric electric fields, J. Geophys. Res.-Space, 110, A05312, https://doi.org/10.1029/2004ja010994, 2005.

Huang, C.-S., de La Beaujardiere, O., Roddy, P. A., Hunton, D. E., Pfaff, R. F., Valladares, C. E., and Ballenthin, J. O.: Evolution of equatorial ionospheric plasma bubbles and formation of broad plasma depletions measured by the C/NOFS satellite during deep solar minimum, J. Geophys. Res.-Space, 116, A03309, https://doi.org/10.1029/2010ja015982, 2011.

Huang, C.-S., de La Beaujardiere, O., Roddy, P. A., Hunton, D. E., Ballenthin, J. O., and Hairston, M. R.: Generation and characteristics of equatorial plasma bubbles detected by the C/NOFS satellite near the sunset terminator, J. Geophys. Res.-Space, 117, A11313, https://doi.org/10.1029/2012ja018163, 2012.

Huang, C.-S., La Beaujardiere, O., Roddy, P., Hunton, D., Liu, J., and Chen, S.: Occurrence probability and amplitude of equatorial ionospheric irregularities associated with plasma bubbles during low and moderate solar activities (2008-2012), J. Geophys. Res.Space, 119, 1186-1199, https://doi.org/10.1002/2013ja019212, 2014.

Huang, C. Y., Burke, W. J., Machuzak, J. S., Gentile, L. C., and Sultan, P. J.: DMSP observations of equatorial plasma bubbles in the topside ionosphere near solar maximum, J. Geophys. Res., 106, 8131-8142, https://doi.org/10.1029/2000JA000319, 2001.

Hysell, D. L. and Seyler, C. E.: A renormalization group approach to estimation of anomalous diffusion in the unstable equatorialFregion, J. Geophys. Res.-Space, 103, 26731-26737, https://doi.org/10.1029/98ja02616, 1998.

Jin, Y., Spicher, A., Xiong, C., Clausen, L. B. N., Kervalishvili, G., Stolle, C., and Miloch, W. J.: Ionospheric Plasma Irregularities Characterized by the Swarm Satellites: Statistics at High Latitudes, J. Geophys. Res.-Space, 124, 1262-1282, https://doi.org/10.1029/2018ja026063, 2019.

Kelley, M.: The Earth's Ionosphere: Plasma Physics and Electrodynamics, International Geophysics, Elsevier Science, available at: https://books.google.co.ug/books?id=3GlWQnjBQNgC (last access: 14 February 2020), 2009.

Keskinen, M. J., Ossakow, S. L., and Fejer, B. G.: Threedimensional nonlinear evolution of equatorial ionospheric spread-F bubbles, Geophys. Res. Lett., 30, 1855 https://doi.org/10.1029/2003gl017418, 2003.

Kikuchi, T., Lühr, H., Kitamura, T., Saka, O., and Schlegel, K.: Direct penetration of the polar electric field to the equator during a DP 2 event as detected by the auroral and equatorial magnetometer chains and the EISCAT radar, J. Geophys. Res-Space, 101, 17161-17173, https://doi.org/10.1029/96ja01299, 1996.

Kil, H. and Heelis, R. A.: Global distribution of density irregularities in the equatorial ionosphere, J. Geophys. Res., 103, 407-418, https://doi.org/10.1029/97JA02698, 1998.

Kil, H., DeMajistre, R., and Paxton, L. J.: F-region plasma distribution seen from TIMED/GUVI and its relation to the equatorial spread F activity, Geophys. Res. Lett., 31, L05810, https://doi.org/10.1029/2003GL018703, 2004.

Kil, H., Paxton, L. J., and Oh, S.-J.: Global bubble distribution seen from ROCSAT-1 and its association with the evening prereversal enhancement, J. Geophys. Res-Space, 114, A06307, https://doi.org/10.1029/2008ja013672, 2009.

Kil, H., Paxton, L. J., Jee, G., and Nikoukar, R.: Plasma blobs associated with medium-scale traveling iono- 
spheric disturbances, Geophys. Res. Lett., 46, 3575-3581, https://doi.org/10.1029/2019gl082026, 2019.

Kintner, P. M., Ledvina, B. M., and de Paula, E. R.: GPS and ionospheric scintillations, Adv. Space Res., 5, 09003, https://doi.org/10.1029/2006SW000260, 2007.

Knudsen, D. J., Burchill, J. K., Buchert, S. C., Eriksson, A. I., Gill, R., Wahlund, J.-E., Åhlen, L., Smith, M., and Moffat, B.: Thermal ion imagers and Langmuir probes in the Swarm electric field instruments, J. Geophys. Res.-Space, 122, 2655-2673, https://doi.org/10.1002/2016ja022571, 2017.

Kumar, S.: Morphology of equatorial plasma bubbles during low and high solar activity years over Indian sector, Astrophys. Space Sci., 362, https://doi.org/10.1007/s10509-017-3074-3, 2017.

Li, G., Ning, B., Liu, L., Wan, W., and Liu, J. Y.: Effect of magnetic activity on plasma bubbles over equatorial and low-latitude regions in East Asia, Ann. Geophys.-Atm. Hydr., 27, 303-312, https://doi.org/10.5194/angeo-27-303-2009, 2009.

Liu, H., Lühr, H., Henize, V., and KöHler, W.: Global distribution of the thermospheric total mass density derived from CHAMP, J. Geophys. Res.-Space, 110, A04301, https://doi.org/10.1029/2004JA010741, 2005.

Liu, H., Stolle, C., Förster, M., and Watanabe, S.: Solar activity dependence of the electron density in the equatorial anomaly regions observed by CHAMP, J. Geophys. Res.-Space, 112, 1-10, https://doi.org/10.1029/2007JA012616, 2007.

Lühr, H., Xiong, C., Park, J., and Rauberg, J.: Systematic study of intermediate-scale structures of equatorial plasma irregularities in the ionosphere based on CHAMP observations, Front. Phys., 2, 1-9, https://doi.org/10.3389/fphy.2014.00015, 2014.

Ma, G. and Maruyama, T.: A super bubble detected by dense GPS network at east Asian longitudes, Geophys. Res. Lett., 33, L21103, https://doi.org/10.1029/2006g1027512, 2006.

Makela, J., Ledvina, B., Kelley, M., and Kintner, P.: Analysis of the seasonal variations of equatorial plasma bubble occurrence observed from Haleakala, Hawaii, Ann. Geophys., 22, 3109-3121, https://doi.org/10.5194/angeo-22-3109-2004, 2004.

McClure, J. P., Singh, S., Bamgboye, D. K., Johnson, F. S., and Kil, H.: Occurrence of equatorial $F$ region irregularities: Evidence for tropospheric seeding, J. Geophys. Res., 103, 29119-29136, https://doi.org/10.1029/98JA02749, 1998.

Muella, M., de Paula, E., Kantor, I., Batista, I., Sobral, J., Abdu, M., Kintner, P., Groves, K., and Smorigo, P.: GPS L-band scintillations and ionospheric irregularity zonal drifts inferred at equatorial and low-latitude regions, J. Atmos. Sol.-Terr. Phys., 70, 1261-1272, https://doi.org/10.1016/j.jastp.2008.03.013, 2008.

Muella, M. T. A. H., Kherani, E. A., de Paula, E. R., Cerruti, A. P., Kintner, P. M., Kantor, I. J., Mitchell, C. N., Batista, I. S., and Abdu, M. A.: Scintillation-producing Fresnel-scale irregularities associated with the regions of steepest TEC gradients adjacent to the equatorial ionization anomaly, J. Geophys. Res.-Space, 115, A03301, https://doi.org/10.1029/2009JA014788, 2010.

Nishioka, M., Saito, A., and Tsugawa, T.: Occurrence characteristics of plasma bubble derived from global ground-based GPS receiver networks, J. Geophys. Res.-Space, 113, A05301, https://doi.org/10.1029/2007ja012605, 2008.

Nishioka, M., Basu, S., Basu, S., Valladares, C. E., Sheehan, R. E., Roddy, P. A., and Groves, K. M.: C/NOFS satellite observations of equatorial ionospheric plasma structures supported by multiple ground-based diagnostics in October 2008, J. Geophys.
Res-Space, 116, A10323, https://doi.org/10.1029/2011ja016446, 2011.

Otsuka, Y.: Review of the generation mechanisms of post-midnight irregularities in the equatorial and low-latitude ionosphere, Prog. Earth Pl. Sc., 5, 1-13, https://doi.org/10.1186/s40645-018-02127, 2018.

Palmroth, M., Laakso, H., Fejer, B. G., and Pfaff Jr., R.: DE 2 observations of morningside and eveningside plasma density depletions in the equatorial ionosphere, J. Geophys. Res-Space, 105, 18429-18442, https://doi.org/10.1029/1999ja005090, 2000.

Park, J., Min, K. W., Kim, V. P., Kil, H., Lee, J.-J., Kim, H.J., Lee, E., and Lee, D. Y.: Global distribution of equatorial plasma bubbles in the premidnight sector during solar maximum as observed by KOMPSAT-1 and Defense Meteorological Satellite Program F15, J. Geophys. Res.-Space, 110, A07308, https://doi.org/10.1029/2004ja010817, 2005.

Pi, X., Mannucci, A. J., Lindqwister, U. J., and Ho, C. M.: Monitoring of global ionospheric irregularities using the Worldwide GPS Network, Geophys. Res. Lett., 24, 2283-2286, https://doi.org/10.1029/97GL02273, 1997.

Portillo, A., Herraiz, M., Radicella, S. M., and Ciraolo, L.: Equatorial plasma bubbles studied using African slant total electron content observations, J. Atmos. Sol.-Terr. Phys., 70, 907-917, https://doi.org/10.1016/j.jastp.2007.05.019, 2008.

Rama Rao, P. V. S., Jayachandran, P. T., Sri Ram, P., Ramana Rao, B. V., Prasad, D. S. V. V. D., and Bose, K. K.: Characteristics of VHF radiowave scintillations over a solar cycle (1983-1993) at a low-latitude station: Waltair $\left(17.7^{\circ} \mathrm{N}, 83.3^{\circ} \mathrm{E}\right)$, Ann. Geophys., 15, 729-733, https://doi.org/10.1007/s00585-997-0729-3, 1997.

Rishbeth, H.: Polarization fields produced by winds in the equatorial F-region, Planet. Space Sci., 19, 357-369, https://doi.org/10.1016/0032-0633(71)90098-5, 1971.

Schunk, R. W. and Nagy, A. F.: Ionospheres: physics, plasma physics, and chemistry, Cambridge Atmospheric and Space Science Series, Cambridge, Cambridge, 2nd Edn., 1-554, 2009.

Sharma, A. K., Gurav, O. B., Gaikwad, H. P., Chavan, G. A., Nade, D. P., Nikte, S. S., Ghodpage, R. N., and Patil, P. T.: Study of equatorial plasma bubbles using all sky imager and scintillation technique from Kolhapur station: a case study, Astrophys. Space Sci., 363, 1-11, https://doi.org/10.1007/s10509-018-33034, 2018.

Sobral, J. H. A., Abdu, M. A., Takahashi, H., Taylor, M. J., de Paula, E. R., Zamlutti, C. J., de Aquino, M. G., and Borba, G. L.: Ionospheric plasma bubble climatology over Brazil based on 22 years (1977-1998) of 630nm airglow observations, J. Atmos. Sol.-Terr. Phys., 64, 1517-1524, https://doi.org/10.1016/S13646826(02)00089-5, 2002.

Spogli, L., Cesaroni, C., Di Mauro, D., Pezzopane, M., Alfonsi, L., Musicò, E., Povero, G., Pini, M., Dovis, F., Romero, R., Linty, N., Abadi, P., Nuraeni, F., Husin, A., Le Huy, M., Lan, T. T., La, T. V., Pillat, V. G., and Floury, N.: Formation of ionospheric irregularities over Southeast Asia during the 2015 St. Patrick's Day storm, J. Geophys. Res.-Space, 121, 12211-12233, https://doi.org/10.1002/2016JA023222, 2016.

Stolle, C., Lühr, H., Rother, M., and Balasis, G.: Magnetic signatures of equatorial spread $\mathrm{F}$ as observed by the CHAMP satellite, J. Geophys. Res.-Space, 111, A02304, https://doi.org/10.1029/2005JA011184, 2006. 
Su, S.-Y., Liu, C., Ho, H., and Chao, C.: Distribution characteristics of topside ionospheric density irregularities: Equatorial versus midlatitude regions, J. Geophys. Res.-Space, 111, A06305, https://doi.org/10.1029/2005ja011330, 2006.

Su, S.-Y., Chao, C. K., and Liu, C. H.: Cause of different local time distribution in the postsunset equatorial ionospheric irregularity occurrences between June and December solstices, J. Geophys. Res.-Space, 114, A04321, https://doi.org/10.1029/2008ja013858, 2009.

Sun, Y. Y., Liu, J. Y., and Lin, C. H.: A statistical study of low latitude $\mathrm{F}$ region irregularities at Brazilian longitudinal sector response to geomagnetic storms during post-sunset hours in solar cycle 23, J. Geophys. Res.-Space, 117, A03333, https://doi.org/10.1029/2011JA017419, 2012.

Tsunoda, R. T.: Control of the seasonal and longitudinal occurrence of equatorial scintillations by the longitudinal gradient in integrated E region Pedersen conductivity, J. Geophys. Res., 90, 447-456, https://doi.org/10.1029/JA090iA01p00447, 1985.

Vichare, G. and Richmond, A. D.: Simulation study of the longitudinal variation of evening vertical ionospheric drifts at the magnetic equator during equinox, J. Geophys. Res.-Space, 110, A05304, https://doi.org/10.1029/2004JA010720, 2005.

Wan, X., Xiong, C., Rodriguez-Zuluaga, J., Kervalishvili, G. N., Stolle, C., and Wang, H.: Climatology of the Occurrence Rate and Amplitudes of Local Time Distinguished Equatorial Plasma Depletions Observed by Swarm Satellite, J. Geophys. Res.Space, 123, 3014-3026, https://doi.org/10.1002/2017JA025072, 2018.

Woodman, R. F.: Spread F - an old equatorial aeronomy problem finally resolved?, Ann. Geophys., 27, 1915-1934, https://doi.org/10.5194/angeo-27-1915-2009, 2009.

Woodman, R. F. and La Hoz, C.: Radar observations of F region equatorial irregularities, J. Geophys. Res., 81, 5447-5466, https://doi.org/10.1029/JA081i031p05447, 1976.

Xiong, C., Park, J., Lühr, H., Stolle, C., and Ma, S. Y.: Comparing plasma bubble occurrence rates at CHAMP and GRACE altitudes during high and low solar activity, Ann. Geophys., 28, 1647-1658, https://doi.org/10.5194/angeo-28-1647-2010, 2010.
Xiong, C., Lühr, H., Ma, S. Y., Stolle, C., and Fejer, B. G.: Features of highly structured equatorial plasma irregularities deduced from CHAMP observations, Ann. Geophys., 30, 1259 1269, https://doi.org/10.5194/angeo-30-1259-2012, 2012.

Xiong, C., Stolle, C., Juan, R. Z., and Siemes, C.: Losses of GPS signals onboard the Swarm satellites and its relation to strong plasma depletions, AGU Fall Meeting Abstracts, SA12A-01, 2016a.

Xiong, C., Stolle, C., and LÜhr, H.: The Swarm satellite loss of GPS signal and its relation to ionospheric plasma irregularities, Adv. Space Res., 14, 563-577, https://doi.org/10.1002/2016SW001439, 2016b.

Xiong, C., Stolle, C., LÜhr, H., Park, J., Fejer, B. G., and Kervalishvili, G. N.: Scale analysis of equatorial plasma irregularities derived from Swarm constellation, Earth Planet. Space, 68, 121, https://doi.org/10.1186/s40623-016-0502-5, $2016 \mathrm{c}$.

Yang, Z. and Liu, Z.: Correlation between ROTI and Ionospheric Scintillation Indices using Hong Kong low-latitude GPS data, GPS Solut., 20, 815-824, https://doi.org/10.1007/s10291-0150492-y, 2015.

Yizengaw, E. and Groves, K. M.: Longitudinal and Seasonal Variability of Equatorial Ionospheric Irregularities and Electrodynamics, Adv. Space Res., 16, 946-968, https://doi.org/10.1029/2018sw001980, 2018.

Yizengaw, E., Moldwin, M. B., Zesta, E., Biouele, C. M., Damtie, B., Mebrahtu, A., Rabiu, B., Valladares, C. F., and Stoneback, R.: The longitudinal variability of equatorial electrojet and vertical drift velocity in the African and American sectors, Ann. Geophys., 32, 231-238, https://doi.org/10.5194/angeo-32-231-2014, 2014.

Zakharenkova, I., Astafyeva, E., and Cherniak, I.: GPS and in situ Swarm observations of the equatorial plasma density irregularities in the topside ionosphere, Earth Planet. Space, 68, 120, https://doi.org/10.1186/s40623-016-0490-5, 2016.

Zargham, S. and Seyler, C. E.: Collisional and inertial dynamics of the ionospheric interchange instability, J. Geophys. Res., 94, 9009-9027, https://doi.org/10.1029/ja094ia07p09009, 1989.

Zou, Y. and Wang, D.: A study of GPS ionospheric scintillations observed at Guilin, J. Atmos. Sol.-Terr. Phys., 71, 1948-1958, https://doi.org/10.1016/j.jastp.2009.08.005, 2009. 